\title{
Diretrizes para o desenvolvimento de empreendimentos Student Housing
}

\author{
Guidelines for the development of Student Housing \\ buildings
}

\author{
Hyago Mauricio Bremm Muller \\ Eliane Monetti \\ José da Costa Marques Neto
}

\section{Resumo}

A

moradia estudantil foi discutida na literatura sob aspectos da preferência e satisfação residencial; fatores indutores de 1 influentes na escolha da moradia. Entretanto, escassos são os trabalhos que abordaram assuntos sobre empreendimentos destinados a estudantes, bem como os novos produtos do mercado imobiliário brasileiro, os empreendimentos denominados Student Housing (SH). Nesse contexto, a presente pesquisa tem como objetivo propor diretrizes para orientar o processo de desenvolvimento de empreendimentos SH. Para esse fim, o estudo propôs, inicialmente, comparar sete edifícios SH para investigar as principais características desse modelo. Tais informações, acrescentadas à revisão da literatura, permitiram explorar, por meio de um levantamento survey, a opinião de estudantes universitários sobre a importância de quatro requisitos preestabelecidos. Os resultados revelam que muitos atributos presentes nos edifícios SH não são considerados importantes ou são indiferentes do ponto de vista dos estudantes, o que demonstra custos adicionais e desnecessários para os investidores. Em contrapartida, o estudo identificou vários atributos valiosos para os usuários. Com base nisso, foram sugeridas doze diretrizes para orientar projetistas, incorporadores e investidores do mercado imobiliário estudantil no desenvolvimento de seus produtos.

Palavras-chave: Moradia estudantil. Estudante universitário. Empreendimento de base imibiliária. Mercado imobiliário. Servitização.

${ }^{1}$ Hyago Mauricio Bremm Muller 1 Universidade Federal de São Carlos São Carlos - SP - Brasil

2Eliane Monetti ZUniversidade de São Paulo São Paulo - SP - Brasil

${ }^{3}$ José da Costa Marques Neto 3Universidade Federal de São Carlos São Carlos - SP - Brasil

Recebido em 25/05/21 Aceito em 12/08/21

\section{Abstract}

Student housing was discussed in the literature under the aspects of residential preference and satisfaction; inducing factors of behavior and demand in the real estate market; and influencing variables in choosing the habitation. However, the works that approach topics about real estate meant for students and the new products of the Brazilian real estate, the ones named Student Housing (SH), are scarce. Within this context, the objective of this research is to propose guidelines to orient the development process of SH buildings. For this purpose, the work proposed, initially, through a comparative study of seven SH real states, to investigate the main characteristics of this product model. Such information, added to the bibliographic review of the literature, allowed the exploration, through a survey, of university students' opinion about the importance of four pre-established requirements. The results revealed that many attributes present in new Brazilian SH buildings are not considered important or are indifferent from the students' point of view, which shows additional and unnecessary costs for investors. In contrast, the study identified several requirements valuable to users. Based on thist, twelve guidelines were suggested to orient the student market designers, developers, and investors in the development of their products.

Keywords: Student housing. College student. Real Estate development. Real estate market. Servitization. 


\section{Introdução}

O mercado de estudantes é frequentemente considerado flexível, uma vez que os estudantes se adaptam facilmente de acordo com a disponibilidade de habitação em uma determinada região. No entanto, esse mercado representa um nicho específico, com características próprias, e o seu desenvolvimento depende de uma série de fatores como:

(a) a demanda substancial;

(b) as preferências de locação das pessoas;

(c) a localização; e

(d) além do tipo de propriedade (RUGG; RHODES; JONES, 2002).

Entender de que modo os alunos gostariam de viver, assim como quais aspectos eles consideram importantes para obter satisfação com relação à moradia, são fatores fundamentais para o planejamento de moradias estudantis e para o desenvolvimento de políticas habitacionais (THOMSEN; EIKEMO, 2010).

Nos Estados Unidos e em vários países da Europa, o nicho de mercado Student Housing já atingiu sua maturidade. No ano de 2018, foram investidos US $\$ 17,1$ bilhões em moradias estudantis no mundo todo, representando um aumento de $425 \%$ quando comparado ao volume investido dez anos atrás (SAVILLS, 2019). De acordo com JLL (JONES..., 2017), as incertezas econômicas e políticas têm contribuído para o surgimento de novos ativos imobiliários para investimento, impulsionados pela crescente demanda em virtude de aspectos como alterações demográficas, aumento da mobilidade, mudanças nos padrões de estilo de vida e avanços tecnológicos. Os mercados que motivaram a demanda por essa classe de ativos na Europa estão diretamente ligados ao aumento expressivo dos programas de cursos em inglês, crescimento acelerado da população estudantil internacional e maiores exigências por alojamentos de melhor qualidade (FRENCH et al., 2018).

Isso evidencia o que muitas pesquisas têm destacado: uma vez que o comportamento das novas gerações está mudando, a porcentagem de alunos com idade tradicional - que são os mais interessados em viver no campus - está se tornando cada vez menor (MCBRIDE, 2017). Os estudantes das novas gerações possuem expectativas mais altas de moradia e estão dispostos a pagarem mais por determinadas comodidades (LA ROCHE; FLANIGAN; COPELAND JUNIOR, 2010). Esses jovens estão buscando mais privacidade e mais controle sobre seus espaços pessoais, além de estarem mais exigentes no que se refere à qualidade da acomodação, almejando quartos equipados e banheiros privativos, bem diferentes das acomodações tradicionais oferecidas pelas universidades, com dormitórios antigos, banheiros e refeitórios compartilhados (KHOZAEI et al., 2014; FRENCH et al., 2018).

Tendo em vista a relevância do mercado imobiliário de estudantes, muitos estudos na literatura internacional discutiram a moradia estudantil sob aspectos da preferência e satisfação residencial (AMOLE, 2009; LA ROCHE; FLANIGAN; COPELAND JUNIOR, 2010; THOMSEN; EIKEMO, 2010; KHOZAEI et al., 2014; MOORE et al., 2019); fatores indutores de comportamento e demanda no mercado imobiliário (RUGG, RHODES; JONES, 2002); e variáveis influentes na escolha da moradia (SHINN, 1971; SUGDEN; WILLIAMS, 1973; HENSHER; TAYLOR, 1983; FIELDS et al., 2013). Na literatura nacional, a discussão do assunto concentra-se na área de psicologia, relação entre moradia e seus impactos sociais e psicológicos (OSSE; COSTA, 2011; GARRIDO, 2012; LACERDA; VALENTINE, 2018). Quando se trata do mercado imobiliário propriamente dito, as pesquisas limitam-se na exploração da preferência de escolha (BRANDLI, 2004); avaliação pós-ocupação (ZANCUL, 2007); e atratividade do mercado de estudantes (PETRI, 2016).

Alguns autores relataram que a literatura brasileira sobre moradias estudantis apresenta-se de maneira limitada e descontínua (GARRIDO, 2012), tal como são as pesquisas que abordam aspectos econômicos, sociais, urbanos e demográficos sobre o mercado imobiliário estudantil (PETRI, 2016). Brandli (2004) ressalva ainda que no Brasil pouca atenção tem sido dada à crescente população de estudantes e às questões relacionadas às suas circunstâncias habitacionais. Embora muitas áreas têm sido cobertas, escassos são os trabalhos que abordaram assuntos sobre empreendimentos destinados a estudantes, bem como os novos produtos do mercado imobiliário brasileiro, mais especificadamente os empreendimentos denominados Student Housing (SH).

Nesse contexto, ressaltam-se lacunas de conhecimento relacionadas à compreensão das principais características que diferenciam os novos produtos do mercado imobiliário brasileiro dos demais imóveis destinados ao público estudantil, e ao entendimento dos anseios e das necessidades demandadas pelos estudantes com relação à moradia, visto que as percepções dos usuários para esse tipo de edificação não 
foram avaliadas. Portanto, esse estudo teve como objetivo propor diretrizes para orientar projetistas, incorporadores e investidores do mercado imobiliário estudantil no desenvolvimento de empreendimentos $\mathrm{SH}$.

\section{Mercado imobiliário estudantil brasileiro e os edifícios $\mathrm{SH}$}

No Brasil, há um número significativo de estudantes universitários, cerca de 8,5 milhões (INSTITUTO..., 2019), o que representa aproximadamente $4 \%$ da população brasileira (INSTITUTO..., 2020). Embora tenha ocorrido um aumento significativo do número de ingressantes em cursos de graduação a distância nos últimos dez anos, os ingressantes em cursos de graduação presenciais ainda representam $60 \%$ do total (INSTITUTO..., 2019). Parte desses estudantes matriculados em cursos presenciais vive nas próprias cidades de origem, sozinhos ou com familiares. Outra parte se desloca para cidades que possuem instituições de ensino superior (IES), o que implica a entrada desses estudantes no mercado imobiliário de locação, por meio do aluguel de algum tipo de moradia.

Segundo Garrido (2012), há dois grandes conjuntos de situações no que diz respeito ao tipo de acomodação utilizada pela população estudantil brasileira. O primeiro grupo é representado pelos estudantes que arcam com as despesas e os custos com moradia durante o período de formação, geralmente bancados por eles próprios, familiares ou parentes. O segundo grupo, por sua vez, é representado por aqueles estudantes que buscam nas IES algum tipo de apoio para garantir um local de habitação durante o período de estudos, motivados pela ausência de condições econômicas deles mesmos e de suas famílias.

As possibilidades disponíveis são diversas, por exemplo: as moradias estudantis universitárias, disponibilizadas pelas universidades federais e financiadas pelo governo, as quais atendem geralmente alunos com pouca ou nenhuma condição financeira. Há também as conhecidas "repúblicas", que são propriedades particulares, geralmente casas, alugadas com o intuito de acomodar muitos estudantes. As repúblicas se apresentam como uma opção para aqueles alunos que estão dispostos a dividir os custos mensais e, com isso, economizar no aluguel e despesas relacionadas à moradia. Outra opção são as moradias do tipo quitinetes, que são apartamentos de proprietários particulares, de pequenas proporções, isto é, com pouca área construída, destinados a estudantes que preferem morar sozinhos ou com poucos colegas.

Além das mencionadas, podem ser citadas mais algumas alternativas de moradia durante o período de estudos, tais como: apartamentos, pensões e residências de familiares. Contudo, ainda existe outra opção, os empreendimentos denominados Student Housing, consolidados em países da Europa e nos Estados Unidos, e relativamente novos no Brasil. Esses empreendimentos apresentam um conceito moderno que se baseia na qualidade do ambiente construído. Os quartos são equipados e mobiliados, há uma diversidade de serviços e facilidades, bem como uma infraestrutura interna completa para estudo, prática de atividades físicas, lazer e entretenimento.

A Figura 1 exemplifica o modelo do produto para o negócio dos empreendimentos $\mathrm{SH}$ que vem sendo ofertado no mercado imobiliário brasileiro.

O principal diferencial dessa tipologia de empreendimento está relacionado à infraestrutura completa disponível aos estudantes, com áreas comuns e privativas. Tal infraestrutura combinada à oferta de serviços e facilidades permite agregar valor e estimular os clientes a pagarem mais por esses benefícios, convertendo esses pagamentos em lucros, conforme evidenciado por Shafer, Smith e Linder (2005).

$\mathrm{O}$ incremento de serviços, junto à principal atividade do negócio (mensalidade de vagas habitacionais), exemplifica o conceito de servitização ${ }^{1}$ proposto por Vandermerwe e Rada (1988), em que se aumenta a oferta de pacotes com foco no cliente. Sendo assim, a empresa que opera o negócio se compromete em melhorar o valor em uso dos clientes (KOWALKOWSKI et al., 2017), que nesse caso são os estudantes. Cabe ressaltar que os empreendimentos do tipo Student Housing e seus serviços associados não podem ser confundidos com empreendimentos do setor hoteleiro, por seus requisitos e peculiaridades.

10 termo "Servitização" é considerado o movimento no qual as empresas acrescentam valor através da adição de serviços em produtos (VANDERMERWE; RADA, 1988). 
Figura 1 - Modelo do produto para o negócio dos empreendimentos Student Housing brasileiro

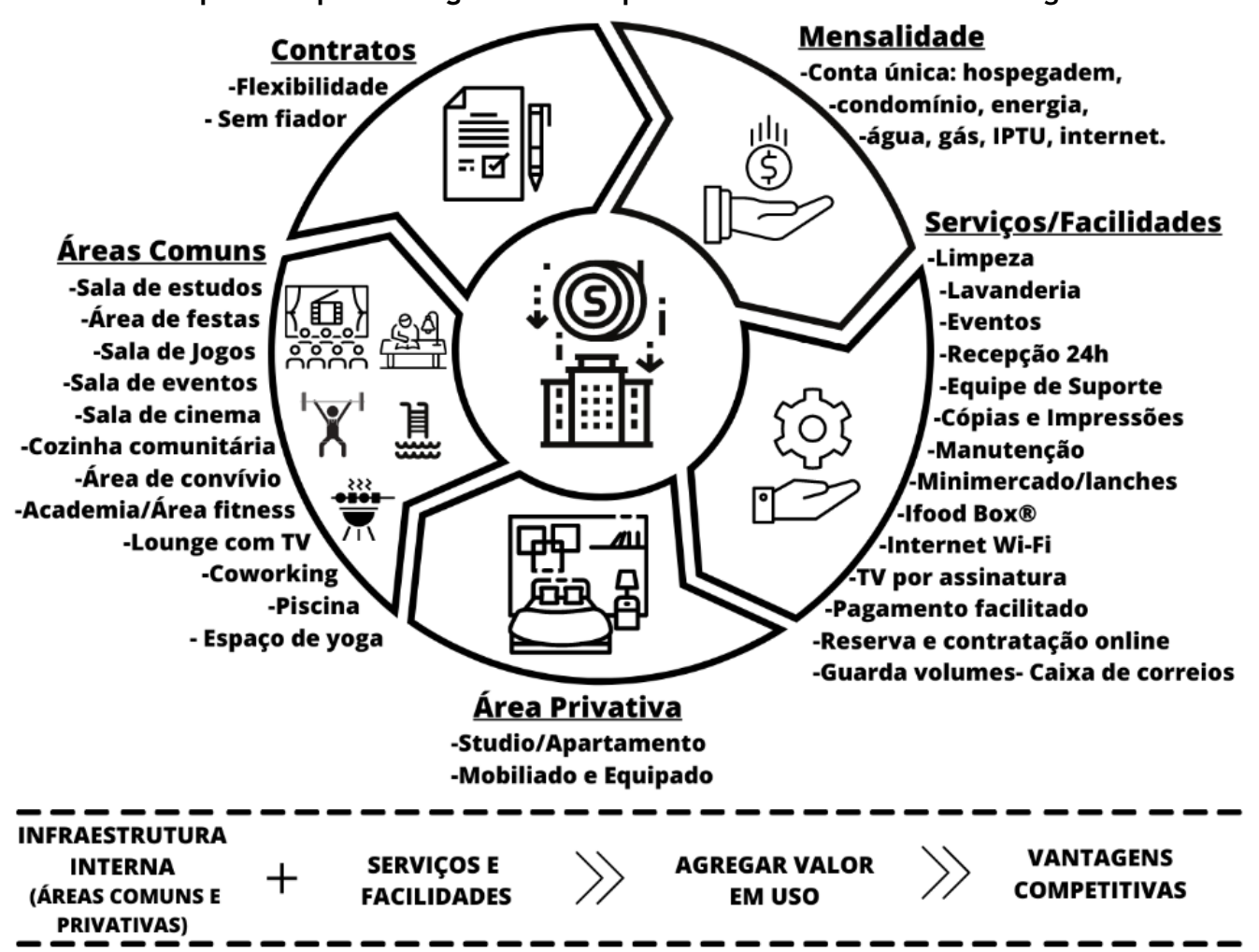

A estratégia de adicionar serviços ao produto permite um modelo de negócio diferenciado, que pode se mostrar mais competitivo e, dessa maneira, trazer vantagens diante dos concorrentes do mercado (SHAFER; SMITH; LINDER, 2005). No caso do mercado imobiliário estudantil, os principais concorrentes são pequenos investidores individuais (donos de quitinetes, apartamentos, casas) e empreendedores (proprietários de repúblicas, pensões, hostel).

De acordo com Teece (2010), descobrir como capturar valor por meio da inovação é um elemento-chave para o sucesso do modelo de negócio. Sendo assim, a inovação apresentada no conceito SH pode mostrar-se como um diferencial para o negócio, permitindo que este permaneça viável durante seu período de operação e, dessa forma, desempenhe a função para qual foi constituído como empreendimento de base imobiliária, em concordância com Rocha Lima Junior, Monetti e Alencar (2011).

\section{Método de pesquisa}

A abordagem metodológica adotada foi o levantamento tipo survey, geralmente utilizada para avaliar uma amostra significativa de um problema a ser investigado, possibilitando extrair conclusões acerca dessa amostra (MIGUEL, 2012). Nesse sentido, com o objetivo de criar uma base teórica para o levantamento survey e, assim, obter melhor compreensão sobre as informações necessárias para a formulação do questionário, o estudo foi conduzido em sete etapas, conforme pode ser visto na Figura 2.

\section{Etapa (a): revisão de literatura}

$\mathrm{Na}$ primeira etapa, foram realizadas buscas em diversos periódicos (artigos, teses e dissertações), com o objetivo de entender o comportamento do mercado imobiliário estudantil e identificar variáveis consideradas importantes de acordo com diferentes estudos e autores. Temas abordando satisfação e preferências na escolha da moradia, influência na seleção de apartamentos, decisão sobre localização, entrada do estudante no mercado imobiliário, relação entre distância e valor do aluguel, comportamento e características do mercado imobiliário estudantil foram identificados. O Quadro 1 ilustra uma síntese dos estudos. 
Figura 2 - Delineamento do método de pesquisa

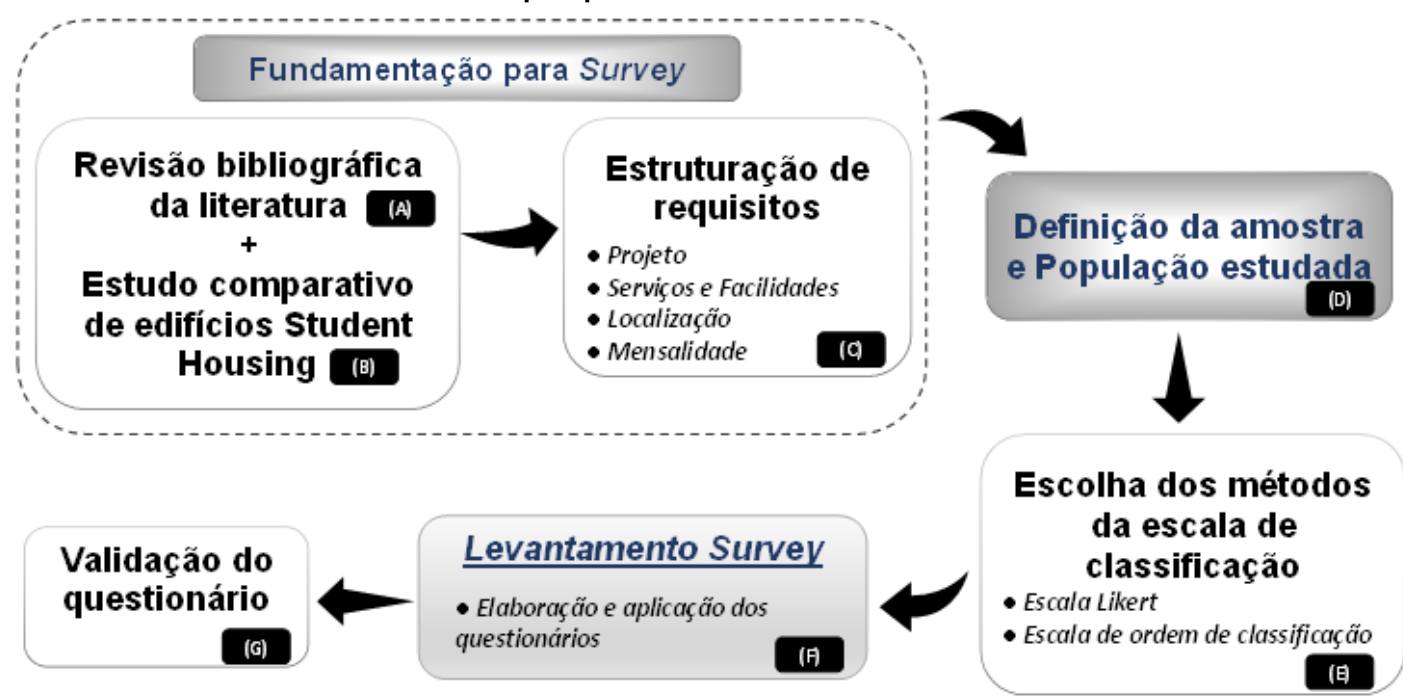

Quadro 1 - Síntese de estudos do mercado imobiliário estudantil

\begin{tabular}{|c|c|c|}
\hline Referência & Estudo/Assunto & Variáveis e fatores considerados mais importantes \\
\hline Shinn (1971) & $\begin{array}{l}\text { Identificação de variáveis determinantes } \\
\text { para escolha da moradia estudantil. }\end{array}$ & Tipo e qualidade da habitação. \\
\hline $\begin{array}{l}\text { Sugden e Williams } \\
\text { (1973) }\end{array}$ & $\begin{array}{l}\text { Padrão de localização dos estudantes de } \\
\text { alojamentos e flats. }\end{array}$ & Custo de viagem para a universidade. \\
\hline $\begin{array}{l}\text { Louviere e Henley } \\
\text { (1977) }\end{array}$ & $\begin{array}{l}\text { Identificação de variáveis influentes na } \\
\text { seleção de apartamentos para moradia } \\
\text { estudantil. }\end{array}$ & $\begin{array}{l}\text { Distância até o campus, qualidade do apartamento e } \\
\text { preço. }\end{array}$ \\
\hline $\begin{array}{l}\text { Hensher e Taylor } \\
\text { (1983) }\end{array}$ & $\begin{array}{l}\text { Decisão dos estudantes na escolha e } \\
\text { mudança de residência durante o período } \\
\text { de estudos. }\end{array}$ & $\begin{array}{l}\text { Acessibilidade à instituição acadêmica, dependência } \\
\text { financeira e composição da residência. }\end{array}$ \\
\hline $\begin{array}{l}\text { Rugg, Rhodes e } \\
\text { Jones (2002) }\end{array}$ & $\begin{array}{l}\text { Impacto da demanda no mercado } \\
\text { imobiliário estudantil. }\end{array}$ & $\begin{array}{l}\text { Concentração intensiva, tipo de propriedade, } \\
\text { intervenção de instituições de ensino superior (IES), } \\
\text { tipo de proprietário, resiliência de mercado. }\end{array}$ \\
\hline \multirow{2}{*}{ Brandli (2004) } & $\begin{array}{l}\text { Motivos que levam os jovens estudantes a } \\
\text { deixarem a casa dos pais e entrarem no } \\
\text { mercado imobiliário. }\end{array}$ & $\begin{array}{l}\text { Tipo de curso, número de disciplinas, dependência } \\
\text { financeira, renda própria, renda dos pais, valor do } \\
\text { apoio financeiro. }\end{array}$ \\
\hline & $\begin{array}{l}\text { Preferência dos estudantes na escolha da } \\
\text { moradia. }\end{array}$ & $\begin{array}{l}\text { Custo da moradia, proximidade com o campus } \\
\text { universitário, habitação com mobília, conforto da } \\
\text { moradia. }\end{array}$ \\
\hline Zancul (2007) & $\begin{array}{l}\text { Avaliação pós-ocupação em habitações } \\
\text { estudantis e fatores de escolha da moradia }\end{array}$ & $\begin{array}{l}\text { Localização, preço do aluguel e condomínio, morar } \\
\text { com amigos, tamanho do apartamento, quarto } \\
\text { individual. }\end{array}$ \\
\hline Amole (2009) & Avaliação da satisfação residencial & $\begin{array}{l}\text { Configurações morfológicas da habitação são } \\
\text { preditoras da satisfação }\end{array}$ \\
\hline $\begin{array}{l}\text { Thomsen e Eikemo } \\
(2010)\end{array}$ & $\begin{array}{l}\text { Aspectos influentes na satisfação com a } \\
\text { moradia estudantil. }\end{array}$ & $\begin{array}{l}\text { Tipo de locação/propriedade, qualidade das } \\
\text { características habitacionais e a localização. }\end{array}$ \\
\hline $\begin{array}{l}\text { La Roche, Flanigan } \\
\text { e Copeland Junior } \\
(2010)\end{array}$ & $\begin{array}{l}\text { Estudo das tendências, preferências e } \\
\text { necessidades dos estudantes por moradias. }\end{array}$ & $\begin{array}{l}\text { Privacidade, estacionamento, mobília, lavanderia, } \\
\text { acesso à internet. }\end{array}$ \\
\hline $\begin{array}{l}\text { Khozaei et al. } \\
(2014)\end{array}$ & $\begin{array}{l}\text { Preferência para atributos do projeto de } \\
\text { residências universitárias. }\end{array}$ & $\begin{array}{l}\text { Preferência por residenciais de estilo suíte, e quartos } \\
\text { individuais com banheiros compartilhados. }\end{array}$ \\
\hline Fields et al. (2013) & $\begin{array}{l}\text { Relação entre a distância e valor do } \\
\text { aluguel. }\end{array}$ & Proximidade entre moradia e campus universitário. \\
\hline Petri (2016) & $\begin{array}{l}\text { Características de preferência pela } \\
\text { moradia estudantil. }\end{array}$ & $\begin{array}{l}\text { Preço, distância entre universidade e moradia e } \\
\text { segurança. }\end{array}$ \\
\hline Moore et al. (2019) & $\begin{array}{l}\text { Satisfação residencial entre estudantes } \\
\text { universitários }\end{array}$ & $\begin{array}{l}\text { Comodidades, tais como piscina e velocidade da } \\
\text { internet aumentam a satisfação residencial. }\end{array}$ \\
\hline
\end{tabular}




\section{Etapa (b): estudo comparativo de edifícios SH}

$\mathrm{Na}$ segunda etapa, foi realizado um estudo comparativo em 7 (sete) edifícios de duas empresas desse ramo no Brasil, com objetivo de identificar as características e atributos comuns nos empreendimentos SH. As duas empresas são pioneiras nesse segmento de mercado, sendo estas as únicas identificadas para realizar o estudo. Já os sete edifícios representam a composição completa do portfólio dessas duas empresas no momento da análise comparativa.

Por motivos confidenciais e estratégicos, os dados para a análise foram obtidos exclusivamente por meio de informações disponibilizadas nos sites oficiais das empresas. Para contribuir com o estudo, de modo a obter melhor entendimento das características físicas e operacionais de um empreendimento $\mathrm{SH}$, foram realizadas visitas técnicas em dois edifícios, sendo um de cada empresa, em que houve uma breve apresentação das funcionalidades e instalações internas.

As propriedades analisadas estão localizadas nas cidades de São Paulo, SP, Ribeirão Preto, SP, e Rio de Janeiro, RJ. Estão inseridos numa zona urbana com alta densidade de construções e, por essa razão, são edifícios verticais de vários andares, que variam entre 12 e 18 andares. Entre os edifícios, quatro deles foram projetados para uso residencial e três para uso hoteleiro. Mais tarde, todos foram adaptados para fins de SH. O Quadro 2 apresenta um checklist dos diversos atributos identificados nos edifícios analisados, e, logo em seguida, serão descritas as principais características de cada quesito identificado.

\section{Infraestrutura interna}

As áreas comuns contam com:

(e) academia/área fitness;

(f) área de convívio;

(g) área de festas com churrasqueira;

(h) cozinha compartilhada;

(i) espaço de yoga;

(j) área comum no andar;

(k) lavanderia;

(l) piscina;

(m) sala de estudos;

(n) sala de eventos;

(o) sala de cinema; e

(p) lounge com TV.

As áreas privativas são todas mobiliadas, sendo que a mobília é uma característica individual de cada acomodação, podendo incluir armários, cama, mesa de estudos, sofá, geladeira, frigobar, ar condicionado, eletrodomésticos e utensílios em geral. Os arranjos das unidades habitacionais são variados, podendo ser do tipo studio (individual ou para duas pessoas), apartamento (duplo ou triplo). Há opções de banheiros compartilhados ou privativos, com ou sem opção de copa, sacada e até com móveis e acabamentos diferenciados. 
Quadro 2 - Checklist de atributos dos empreendimentos analisados

\begin{tabular}{|c|c|c|c|c|c|c|c|}
\hline \multirow{2}{*}{ Atributos } & \multicolumn{7}{|c|}{ Empreendimentos } \\
\hline & $\mathbf{A}$ & $\mathbf{B}$ & $\mathbf{C}$ & D & $\mathbf{E}$ & $\mathbf{F}$ & $\mathbf{G}$ \\
\hline \multicolumn{8}{|c|}{ Infraestrutura interna } \\
\hline \multicolumn{8}{|l|}{ Áreas comuns } \\
\hline Academia/área fitness & & & & & $\mathrm{P}$ & $\mathrm{P}$ & $\mathrm{P}$ \\
\hline Área comum no andar & & & & & & $\mathrm{P}$ & $\mathrm{P}$ \\
\hline Área de convívio/solário/jardim & $\mathrm{P}$ & $\mathrm{P}$ & & $\mathrm{P}$ & $\mathrm{P}$ & $\mathrm{P}$ & $\mathrm{P}$ \\
\hline Área de festas com churrasqueira & $\mathrm{P}$ & & & & $\mathrm{P}$ & $\mathrm{P}$ & $\mathrm{P}$ \\
\hline Bicicletário & & & $\mathrm{P}$ & & $\mathrm{P}$ & $\mathrm{P}$ & $\mathrm{P}$ \\
\hline Coworking & & $\mathrm{P}$ & $\mathrm{P}$ & & & & \\
\hline Cozinha compartilhada/comunitária & $\mathrm{P}$ & $\mathrm{P}$ & $\mathrm{P}$ & $\mathrm{P}$ & $\mathrm{P}$ & $\mathrm{P}$ & $\mathrm{P}$ \\
\hline Espaço de yoga & & & & & & $\mathrm{P}$ & \\
\hline Estacionamento & & & & $\mathrm{P}$ & $\mathrm{P}$ & $\mathrm{P}$ & \\
\hline Lavanderia & $\mathrm{P}$ & $\mathrm{P}$ & $\mathrm{P}$ & $\mathrm{P}$ & $\mathrm{P}$ & $\mathrm{P}$ & $\mathrm{P}$ \\
\hline Piscina & & $\mathrm{P}$ & & & $\mathrm{P}$ & $\mathrm{P}$ & $\mathrm{P}$ \\
\hline Sala de estudos & $\mathrm{P}$ & & & $\mathrm{P}$ & $\mathrm{P}$ & $\mathrm{P}$ & $\mathrm{P}$ \\
\hline Sala de eventos & & & & & $\mathrm{P}$ & $\mathrm{P}$ & $\mathrm{P}$ \\
\hline Sala de cinema & & & & & $\mathrm{P}$ & $\mathrm{P}$ & \\
\hline Sala de jogos & & $\mathrm{P}$ & & $\mathrm{P}$ & $\mathrm{P}$ & $\mathrm{P}$ & $\mathrm{P}$ \\
\hline Lounge com TV & $\mathrm{P}$ & $\mathrm{P}$ & $\mathrm{P}$ & $\mathrm{P}$ & $\mathrm{P}$ & $\mathrm{P}$ & $\mathrm{P}$ \\
\hline \multicolumn{8}{|l|}{ Áreas privativas } \\
\hline Apartamento mobiliado & $\mathrm{P}$ & $\mathrm{P}$ & $\mathrm{P}$ & $\mathrm{P}$ & $\mathrm{P}$ & $\mathrm{P}$ & $\mathrm{P}$ \\
\hline $\begin{array}{l}\text { Apartamento equipado (eletrodomésticos e } \\
\text { utensílios) }\end{array}$ & $\mathrm{P}$ & $\mathrm{P}$ & $\mathrm{P}$ & $\mathrm{P}$ & $\mathrm{P}$ & $\mathrm{P}$ & $\mathrm{P}$ \\
\hline Diversidade de arranjos (apartamento/studio) & & $\mathrm{P}$ & $\mathrm{P}$ & & & $\mathrm{P}$ & $\mathrm{P}$ \\
\hline Cozinha/copa privativa & $\mathrm{P}$ & & $\mathrm{P}$ & & & $\mathrm{P}$ & $\mathrm{P}$ \\
\hline Varanda/sacada & & $\mathrm{P}$ & $\mathrm{P}$ & & $\mathrm{P}$ & & \\
\hline Ar condicionado & & $\mathrm{P}$ & $\mathrm{P}$ & $\mathrm{P}$ & $\mathrm{P}$ & $\mathrm{P}$ & $\mathrm{P}$ \\
\hline Fechadura eletrônica & $\mathrm{P}$ & $\mathrm{P}$ & $\mathrm{P}$ & $\mathrm{P}$ & $\mathrm{P}$ & $\mathrm{P}$ & $\mathrm{P}$ \\
\hline \multicolumn{8}{|c|}{ Serviços e facilidades } \\
\hline \multicolumn{8}{|l|}{ Serviços inclusos } \\
\hline Cópias e impressões & & & & & $\mathrm{P}$ & $\mathrm{P}$ & $\mathrm{P}$ \\
\hline $\begin{array}{l}\text { Eventos (festas, palestras, grupos de esporte, } \\
\text { cinema) }\end{array}$ & $\mathrm{P}$ & $\mathrm{P}$ & $\mathrm{P}$ & $\mathrm{P}$ & $\mathrm{P}$ & $\mathrm{P}$ & $\mathrm{P}$ \\
\hline Recepção 24 horas por dia & $\mathrm{P}$ & & $\mathrm{P}$ & $\mathrm{P}$ & $\mathrm{P}$ & $\mathrm{P}$ & $\mathrm{P}$ \\
\hline Equipe de suporte aos moradores & & $\mathrm{P}$ & & $\mathrm{P}$ & $\mathrm{P}$ & $\mathrm{P}$ & $\mathrm{P}$ \\
\hline Internet wi-fi na unidade (área privativa) & $\mathrm{P}$ & $\mathrm{P}$ & $\mathrm{P}$ & $\mathrm{P}$ & & $\mathrm{P}$ & $\mathrm{P}$ \\
\hline Internet wi-fi em áreas comuns & $\mathrm{P}$ & $\mathrm{P}$ & $\mathrm{P}$ & $\mathrm{P}$ & $\mathrm{P}$ & $\mathrm{P}$ & $\mathrm{P}$ \\
\hline \multicolumn{8}{|l|}{ Serviços opcionais } \\
\hline Serviços de lavanderia & $\mathrm{P}$ & $\mathrm{P}$ & $\mathrm{P}$ & $\mathrm{P}$ & & $\mathrm{P}$ & $\mathrm{P}$ \\
\hline Manutenção da unidade & $\mathrm{P}$ & $\mathrm{P}$ & $\mathrm{P}$ & $\mathrm{P}$ & $\mathrm{P}$ & $\mathrm{P}$ & $\mathrm{P}$ \\
\hline Aluguel de bicicletas & & & & & $\mathrm{P}$ & $\mathrm{P}$ & $\mathrm{P}$ \\
\hline Minimercado/lanches & $\mathrm{P}$ & & & & $\mathrm{P}$ & $\mathrm{P}$ & $\mathrm{P}$ \\
\hline $\begin{array}{l}\text { iFood Box (armário para armazenamento dos } \\
\text { pedidos) }\end{array}$ & & & & & $\mathrm{P}$ & & \\
\hline Limpeza da unidade (semanal/mensal) & $\mathrm{P}$ & $\mathrm{P}$ & $\mathrm{P}$ & $\mathrm{P}$ & $\mathrm{P}$ & $\mathrm{P}$ & $\mathrm{P}$ \\
\hline TV por assinatura na unidade (área privativa) & & $\mathrm{P}$ & & & $\mathrm{P}$ & & \\
\hline \multicolumn{8}{|l|}{ Facilidades } \\
\hline Conta única (tudo incluso) & $\mathrm{P}$ & $\mathrm{P}$ & $\mathrm{P}$ & & $\mathrm{P}$ & $\mathrm{P}$ & $\mathrm{P}$ \\
\hline Contratos flexíveis (mais curtos) & $\mathrm{P}$ & & & & $\mathrm{P}$ & $\mathrm{P}$ & $\mathrm{P}$ \\
\hline Contratos sem fiador/seguro fiança & $\mathrm{P}$ & & & & $\mathrm{P}$ & $\mathrm{P}$ & $\mathrm{P}$ \\
\hline $\begin{array}{l}\text { Facilidade de pagamento (cartão de } \\
\text { crédito/boleto bancário/Paypal) }\end{array}$ & $\mathrm{P}$ & $\mathrm{P}$ & $\mathrm{P}$ & $\mathrm{P}$ & $\mathrm{P}$ & $\mathrm{P}$ & $\mathrm{P}$ \\
\hline Reserva e contratação online & $\mathrm{P}$ & $\mathrm{P}$ & $\mathrm{P}$ & & $\mathrm{P}$ & $\mathrm{P}$ & $\mathrm{P}$ \\
\hline Caixa de correios individual & $\mathrm{P}$ & & & & $\mathrm{P}$ & $\mathrm{P}$ & $\mathrm{P}$ \\
\hline Guarda volumes individual & $\mathrm{P}$ & & & $\mathrm{P}$ & & & \\
\hline \multicolumn{8}{|c|}{ Localização } \\
\hline Proximidade com instituição de ensino & $\mathrm{P}$ & $\mathrm{P}$ & $\mathrm{P}$ & $\mathrm{P}$ & $\mathrm{P}$ & $\mathrm{P}$ & $\mathrm{P}$ \\
\hline Proximidade com bancos & $\mathrm{P}$ & $\mathrm{P}$ & $\mathrm{P}$ & $\mathrm{P}$ & $\mathrm{P}$ & $\mathrm{P}$ & $\mathrm{P}$ \\
\hline Proximidade com bares/ lanchonetes/restaurantes & $\mathrm{P}$ & $\mathrm{P}$ & $\mathrm{P}$ & $\mathrm{P}$ & $\mathrm{P}$ & $\mathrm{P}$ & $\mathrm{P}$ \\
\hline Proximidade com supermercados & & $\mathrm{P}$ & $\mathrm{P}$ & $\mathrm{P}$ & $\mathrm{P}$ & $\mathrm{P}$ & $\mathrm{P}$ \\
\hline Proximidade com farmácias & $\mathrm{P}$ & $\mathrm{P}$ & $\mathrm{P}$ & $\mathrm{P}$ & $\mathrm{P}$ & $\mathrm{P}$ & $\mathrm{P}$ \\
\hline Proximidade com hospitais & $\mathrm{P}$ & $\mathrm{P}$ & $\mathrm{P}$ & $\mathrm{P}$ & $\mathrm{P}$ & $\mathrm{P}$ & $\mathrm{P}$ \\
\hline Proximidade com rodoviária municipal & & & & $\mathrm{P}$ & & & \\
\hline Proximidade com shoppings & $\mathrm{P}$ & $\mathrm{P}$ & $\mathrm{P}$ & $\mathrm{P}$ & $\mathrm{P}$ & $\mathrm{P}$ & $\mathrm{P}$ \\
\hline Proximidade com transporte público & $\mathrm{P}$ & $\mathrm{P}$ & $\mathrm{P}$ & $\mathrm{P}$ & $\mathrm{P}$ & $\mathrm{P}$ & $\mathrm{P}$ \\
\hline
\end{tabular}

Fonte: elaborado com base em Uliving Brasil (2020) e Share Student Living (2020). 


\section{Serviços e facilidades}

Os empreendimentos possuem diversos serviços, alguns deles são inclusos na mensalidade e outros são opcionais. Dos serviços inclusos pode-se citar:

(a) acesso livre à cópia e impressões;

(b) internet wi-fi nas áreas comuns;

(c) internet wi-fi e TV por assinatura nas unidades habitacionais;

(d) recepção (24 horas);

(e) equipe de suporte aos moradores;

(f) iFood Box;

(g) realização de eventos (churrascos, pizza em grupo, halloween, festa fantasia, grupos de esporte, cinema, palestras sobre finanças e culinária); e

(h) entre outros.

Alguns serviços são opcionais, tais como: limpeza da unidade, o qual pode estar incluso no contrato do morador ou ser contratado conforme a demanda. Em geral, os contratos permitem uma limpeza semanal. Há também disponibilidade de serviços de aluguel de bicicletas elétricas, em que o usuário paga por hora de uso; serviços de lavanderia, em que o usuário paga uma taxa por ciclo de lavagem.

As facilidades disponíveis incluem caixa de correios e guarda-volume individual; contratos flexíveis, geralmente de 12 meses, sem necessidade de fiador. As multas obedecem às leis de locação residencial. A conta é única para pagamento, que inclui hospedagem, condomínio, manutenção, IPTU, água, gás, internet e TV a cabo. Em alguns empreendimentos há opção de reserva on-line, bem como facilidade de pagamento através de cartão de crédito, boleto bancário ou Paypal.

\section{Localização}

Em geral, todos os empreendimentos estão situados em pontos estratégicos de modo a atender as necessidades do público-alvo. Ficam próximos a instituições de ensino (universidades, faculdades, escolas), com fácil acesso a transporte público (metrô e/ou ônibus), próximos também a bancos, restaurantes, bares, lanchonetes, farmácias, hospitais, shoppings. Em alguns casos, como nos imóveis localizados no interior de São Paulo, a proximidade da rodoviária municipal é um item considerado fundamental pelos desenvolvedores.

\section{Arranjos e valores}

As rendas são cobradas em forma de mensalidade, o valor ${ }^{2}$ varia de acordo com o arranjo da unidade e itens inclusos no contrato. O preço mínimo de mensalidade encontrado foi de $\mathrm{R} \$ 870,00$, para apartamento triplo com banheiro compartilhado, incluindo na mensalidade hospedagem, condomínio, manutenção, IPTU, água, luz e internet. O preço máximo foi de $\mathrm{R} \$ 4.400,00$ para studio individual com cama de casal, banheiro privativo, móveis e acabamentos diferenciados, incluindo na mensalidade hospedagem, condomínio, manutenção, IPTU, luz, água, gás, internet, limpeza semanal, TV a cabo e uso semanal da lavanderia.

\section{Etapa (c): estruturação dos requisitos a serem explorados}

Por meio da revisão bibliográfica da literatura e da identificação de atributos presentes em empreendimentos $\mathrm{SH}$, resultados das etapas (b) e (c), respectivamente, observou-se quatro requisitos considerados fundamentais a serem explorados, prevalecendo o objetivo desta pesquisa de compreender as necessidades e as preferências no que se refere à escolha da habitação, com base no modelo SH. A Figura 3 ilustra um esquema dos requisitos que serão avaliados.

${ }^{2}$ Valores referentes ao ano de 2020. Salário mínimo: $\mathrm{R} \$ 1.045,00$. 


\section{Etapa (d): definição da amostra e população estudada}

Para o presente estudo optou-se pela utilização da amostragem por conveniência. A principal justificativa da escolha foi devido à facilidade de acesso aos participantes, baixo custo, bem como uma alternativa para o momento de distanciamento social causado pela pandemia da Covid-19. Segundo Etikan, Musa e Alkassim (2016), a amostragem por conveniência é uma técnica não probabilística, utilizada geralmente quando a população pesquisada não é bem definida ou quando os sujeitos são escolhidos pela proximidade com o pesquisador e disposição de participar.

Dessa maneira, o estudo limitou-se a quantidade de indivíduos que se dispuseram a participar, contudo o direcionamento dos questionários foi para estudantes de IES, devidamente matriculados em cursos de graduação ou pós-graduação de universidades, faculdades e institutos federais, e que estudam na cidade de São Carlos, SP, a qual está situada a $235 \mathrm{~km}$ da capital São Paulo, SP.

\section{Etapa (e): escolha dos métodos da escala de classificação}

A fim de estruturar as respostas do questionário e obter melhor análise do estudo, foram utilizados dois métodos diferentes de escala de classificação. O primeiro refere-se à escala Likert, amplamente utilizada nos questionários para medir opiniões, percepções e comportamentos. De acordo com Malhotra, Nunan e Birks (2017), as principais vantagens em se utilizar essa escala é devido à facilidade de construir e administrar as perguntas, assim como o entendimento do uso pelos participantes, mostrando-se adequada para pesquisa online.

O segundo método escolhido foi a escala de ordem de classificação, que consiste em uma técnica de escala comparativa na qual os participantes são apresentados a vários objetos simultaneamente e solicitados para ordená-los ou classificá-los de acordo com algum critério (MALHOTRA; NUNAN; BIRKS, 2017). Nesta pesquisa, em virtude da elevada quantidade de itens a serem avaliados, optou-se pela utilização da abordagem proposta por Carvalho e Leite (1999), porém com classificação dos três primeiros atributos mais importantes, a fim de reduzir o risco de fadiga dos avaliadores e manter uma medida competitiva de importância para cada atributo.

Figura 3 - Requisitos fundamentais a serem explorados para análise da habitação em empreendimentos Student Housing

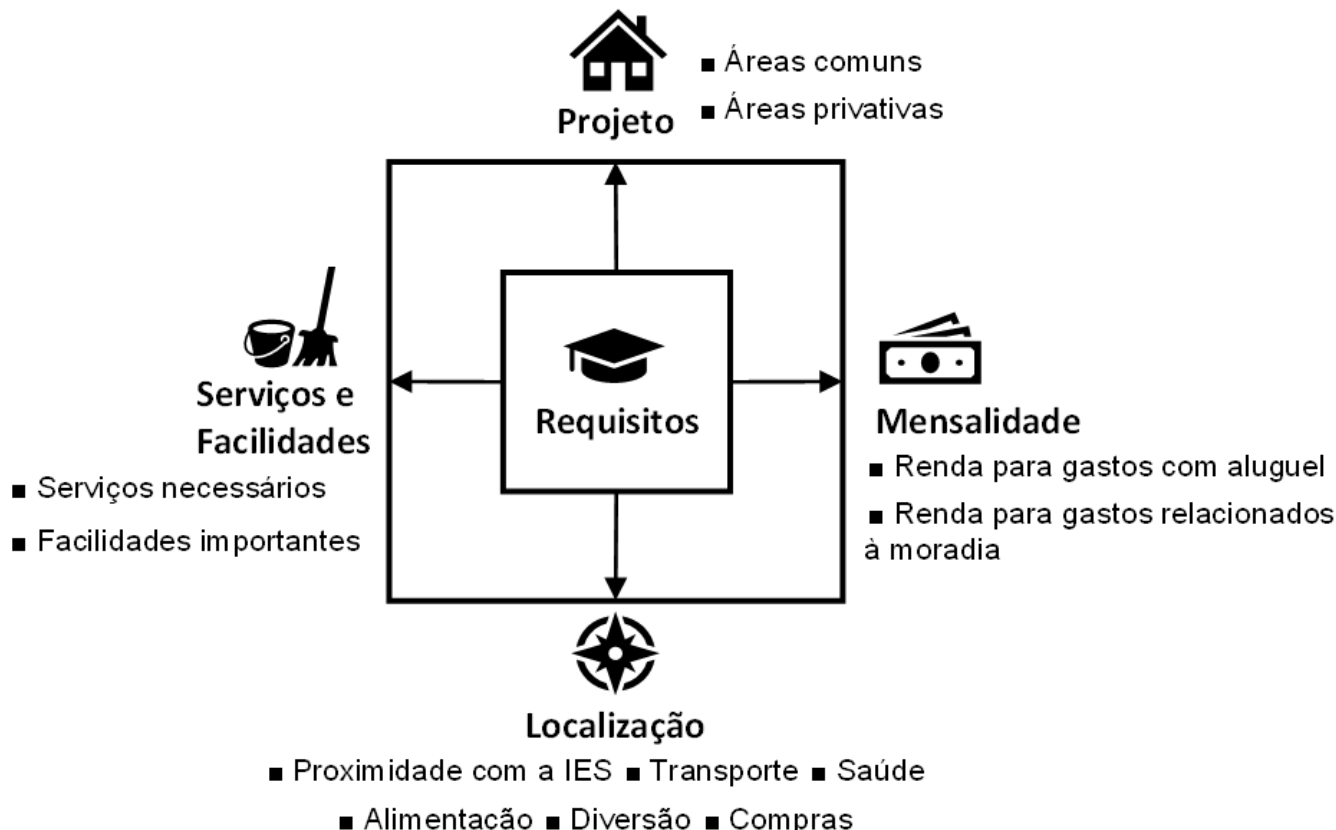


Portanto, os participantes devem classificar os três atributos mais importantes em ordem ascendente. Subsequentemente, foi calculado o valor ponderado de cada item, multiplicando a frequência de cada item por um determinado peso, que foi arbitrariamente assumido da seguinte forma:

(a) peso 3 (três) para o mais importante;

(b) 2 (dois) para o segundo mais importante; e

(c) 1 (um) para o terceiro item mais importante.

\section{Etapa (f): elaboração e aplicação dos questionários}

Os questionários foram elaborados no Google Formulários, incluindo instruções para o preenchimento com explicação dos objetivos da investigação e uma declaração de confidencialidade dos dados individuais. A aprovação ética foi obtida do Comitê de Ética em Pesquisas em Seres Humanos da Universidade Federal de São Carlos sob o número de aprovação CAAE: 28266720.4.0000.5504. Para aplicação dos questionários, optou-se pela utilização da pesquisa on-line basicamente por cinco razões: rapidez, alcance, custo e qualidade da resposta, e distanciamento social (Covid-19).

As perguntas foram divididas em cinco seções.

A primeira delas destinou-se a obter informações pessoais que caracterizam as pessoas a serem pesquisadas, tais como: nome, idade, gênero, tipo de moradia, quantidade de pessoas que vivem na moradia. A segunda seção visava recolher informações relacionadas à opinião dos entrevistados sobre requisitos de localização. A terceira seção destinou-se às informações sobre requisitos de mensalidade, contendo perguntas sobre renda disponível para gastos com aluguel e despesas relacionadas à moradia. $\mathrm{Na}$ quarta seção foram inseridas perguntas sobre requisitos de serviços e facilidades. Na última seção foram elaboradas questões a respeito de requisitos projetuais.

Vale mencionar que foi realizado um pré-teste do questionário com uma população-alvo de dez pessoas para verificar a exatidão e consistência das respostas. Sendo assim, os seguintes aspectos foram modificados: correção da configuração da fonte do Google Formulários para a melhor visualização, diminuição da quantidade de questões, inclusão de uma breve apresentação sobre o conceito de empreendimentos SH para a melhor compreensão dos participantes, e, por último, inserção de observações para o preenchimento das respostas nas questões de ranking. Depois dos ajustes, convites foram enviados para a participação nos questionários por meio de grupos de redes sociais (WhatsApp e Facebook), sendo esses grupos específicos de estudantes universitários e de aluguel de moradia.

\section{Etapa (g): validação do questionário}

Após a coleta de dados, o questionário foi submetido a um teste de confiabilidade utilizando o alfa de Cronbach com auxílio do software SPSS. O valor encontrado para o alfa de Cronbach foi de 0,874, o que representa uma consistência interna quase perfeita de acordo com Landis e Koch (1977). Isso demonstra que o instrumento de coleta de dados é confiável e que as respostas obtidas a partir dele podem ser consideradas válidas.

\section{Resultados e discussões}

\section{Caracterização dos participantes}

No total, 125 estudantes participaram do levantamento survey. A Tabela 1 apresenta informações relativas às características dos participantes desta pesquisa. De maneira geral, os participantes estão divididos entre homens $(52 \%)$ e mulheres $(48 \%)$, são estudantes de pós-graduação $(58 \%)$ e graduação (42\%), e a maioria (68\%) tem idade entre 20 e 28 anos. A maior parte vive em apartamentos (58\%), com até 3 pessoas $(78 \%)$, não possui automóvel (64\%), vai à instituição de ensino a pé, de carro ou transporte público (85\%), e considera o valor do aluguel e despesas relacionadas à moradia como o principal fator de escolha da habitação (61\%).

\section{Requisitos de mensalidade}

Os resultados apresentados na Tabela 2 mostraram que há uma predominância de respostas, em que a maioria dos participantes possui renda para gastos com aluguel da moradia de até R\$1.000,00 (89\%) e renda 
para gastos relacionados à moradia de até $\mathrm{R} \$ 500,00$ (91\%). Somados os valores, representam cerca de 1,5 salário mínimo referente ao período de março de 2020 - valores que se assemelham com dados de outro estudo, na mesma proporção de salário mínimo, mas em outra época (BRANDLI, 2004).

Tabela 1 - Caracterização dos participantes

\begin{tabular}{|c|c|c|}
\hline Características dos participantes & Frequência & $\begin{array}{l}\text { Frequência } \\
\text { relativa }(\%)\end{array}$ \\
\hline \multicolumn{3}{|l|}{ Gênero } \\
\hline Masculino & 60 & 48 \\
\hline Feminino & 65 & 52 \\
\hline \multicolumn{3}{|l|}{ Idade } \\
\hline $17-19$ & 15 & 12 \\
\hline $20-22$ & 25 & 20 \\
\hline $23-25$ & 32 & 26 \\
\hline $26-28$ & 27 & 22 \\
\hline $29-31$ & 16 & 13 \\
\hline Acima de 31 & 16 & 8 \\
\hline \multicolumn{3}{|c|}{ Nível acadêmico que está cursando } \\
\hline Graduação & 52 & 42 \\
\hline Pós-graduação & 73 & 58 \\
\hline \multicolumn{3}{|l|}{ Tipo de moradia } \\
\hline Apartamento & 70 & 56 \\
\hline Quitinete & 22 & 18 \\
\hline República & 12 & 10 \\
\hline Casa & 12 & 10 \\
\hline Moradia estudantil universitária & 6 & 5 \\
\hline Pensão & 3 & 2 \\
\hline \multicolumn{3}{|c|}{ Número de indivíduos da moradia } \\
\hline 1 pessoa & 34 & 27 \\
\hline 2 pessoas & 36 & 29 \\
\hline 3 pessoas & 27 & 22 \\
\hline 4 pessoas & 8 & 6 \\
\hline 5 ou mais pessoas & 20 & 16 \\
\hline \multicolumn{3}{|c|}{ Meio de transporte mais utilizado para ir a IES } \\
\hline Carro & 39 & 31 \\
\hline A pé & 39 & 31 \\
\hline Transporte público & 29 & 23 \\
\hline Outro (carona, van, aplicativo) & 9 & 7 \\
\hline Moto & 6 & 5 \\
\hline Bicicleta & 3 & 2 \\
\hline \multicolumn{3}{|c|}{ Proprietário de automóveis } \\
\hline Sim & 45 & 36 \\
\hline Não & 80 & 64 \\
\hline \multicolumn{3}{|c|}{$\begin{array}{l}\text { Fator de escolha da moradia } \\
\end{array}$} \\
\hline Valor do aluguel e despesas relacionadas à moradia & 76 & 61 \\
\hline Localização da moradia & 35 & 28 \\
\hline Qualidade e atributos da edificação & 10 & 8 \\
\hline Experiência (convivência e amizades) & 2 & 2 \\
\hline Os serviços disponíveis & 2 & 2 \\
\hline
\end{tabular}


Tabela 2 - Requisitos de mensalidade para gastos com aluguel da moradia e gastos relacionado à moradia

\begin{tabular}{|c|c|c|}
\hline Renda disponível para gastos com aluguel da moradia & Frequência & Frequência relativa \\
\hline $\begin{array}{l}\text { Até } \mathrm{R} \$ 500,00 \\
\mathrm{R} \$ 501,00 \text { a } \mathrm{R} \$ 1.000,00 \\
\mathrm{R} \$ 1.001,00 \text { a } \mathrm{R} \$ 1.500,00 \\
\mathrm{R} \$ 1.501,00 \text { a } \mathrm{R} \$ 2.000,00 \\
\text { Acima de } \mathrm{R} \$ 2.000,00\end{array}$ & $\begin{array}{c}54 \\
57 \\
11 \\
1 \\
2 \\
\end{array}$ & $\begin{array}{r}43,2 \% \\
45,6 \% \\
8,8 \% \\
0,8 \% \\
1,6 \% \\
\end{array}$ \\
\hline $\begin{array}{l}\text { Renda disponível para gastos relacionado à moradia (internet, } \\
\text { água, energia, gás, condomínio, lavanderia, limpeza) }\end{array}$ & Frequência & Frequência relativa \\
\hline $\begin{array}{l}\text { Até } \mathrm{R} \$ 250,00 \\
\mathrm{R} \$ 251,00 \text { a } \mathrm{R} \$ 500,00 \\
\mathrm{R} \$ 501,00 \text { a } \mathrm{R} \$ 750,00 \\
\mathrm{R} \$ 751,00 \text { a } \mathrm{R} \$ 1.000,00 \\
\text { Acima de } \mathrm{R} \$ 1.000,00\end{array}$ & $\begin{array}{l}76 \\
38 \\
5 \\
4 \\
2\end{array}$ & $\begin{array}{c}60,8 \% \\
30,4 \% \\
4,0 \% \\
3,2 \% \\
1,6 \%\end{array}$ \\
\hline
\end{tabular}

\section{Requisitos de localização}

Com relação à localização, os resultados ilustrados na Tabela 3 mostraram que há uma importância superior no quesito proximidade da moradia à IES, o que corrobora com estudos realizados anteriormente, indicando que os estudantes preferem viver próximo ao local onde estudam (BRANDLI, 2004; FIELDS et al., 2013; HENSHER; TAYLOR, 1983) e que moradias localizadas distantes do campus universitário dificilmente são escolhidas, independentemente de quão bons sejam outros fatores (LOUVIERE; HENLEY, 1977). Em seguida, os achados apontaram que, além do quesito proximidade da IES, os estudantes consideram importante que suas moradias estejam próximas a supermercados, com fácil acesso ao transporte público. Esses três tópicos obtiveram os valores médios mais elevados pela escala Likert e as pontuações mais altas na avaliação por escala de ordem de classificação. Por outro lado, destacam-se entre os menos importantes: proximidade com shoppings, hospitais e bancos.

\section{Requisitos de serviços}

É possível observar a partir da Tabela 4 que a maioria dos serviços foram classificados pelos participantes como importante ou muito importante na escala Likert, enquanto na escala de ordem de classificação destacaram-se os serviços:

(a) internet wi-fi na unidade (área privativa);

(b) recepção (24 horas); e

(c) limpeza da unidade (área privativa).

De maneira geral, é possível perceber que em ambas escalas os serviços mais importantes que se destacaram foram:

(a) internet wi-fi na unidade (área privativa);

(b) recepção (24 horas);

(c) limpeza e manutenção da unidade (área privativa);

(d) minimercado/lanches;

(e) serviços de lavanderia;

(f) serviços de cópias e impressões;

(g) internet wi-fi em áreas comuns; e

(h) equipe de suporte aos moradores.

Em contrapartida, destacam-se entre os serviços menos importantes:

(a) TV por assinatura na unidade (área privativa);

(b) aluguel de bicicletas; 
(c) disponibilidade de eventos; e

(d) iFood Box.

\section{Requisitos de facilidades}

Os resultados ilustrados na Tabela 5 mostraram que existe uma importância superior nas facilidades contratos flexíveis (curtos), conta única (tudo incluso), contratos sem fiador/seguro fiança e facilidade de pagamento. Esses quatro atributos obtiveram as pontuações mais elevadas na avaliação por escada de ordem de classificação e também os valores médios mais elevados na escada Likert. Por outro lado, destacam-se entre os menos importantes:

(a) reserva e contratação on-line;

(b) guarda-volume; e

(c) caixa de correios individual.

\section{Requisitos de projeto}

É possível verificar a partir da Tabela 6 que existe uma importância superior nas áreas comuns:

(a) sala de estudos;

(b) academia/áreas fitness;

(c) área de festas com churrasqueira; $\mathrm{e}$

(d) área de convívio/solário/jardim.

Esses quatro tópicos obtiveram os valores médios mais elevados na escala Likert e as pontuações mais altas na avaliação por escala de ordem de classificação. Em contrapartida, destacam-se entre os ambientes menos importantes lounge com TV, sala de cinema e espaço de yoga.

Tabela 3 - Importância dos requisitos de localização por escada Likert e escala de ordem de classificação

\begin{tabular}{|c|c|c|c|c|c|c|c|c|c|c|c|c|c|c|}
\hline \multirow[b]{3}{*}{ Localização } & \multicolumn{3}{|c|}{ Medidas } & \multirow{2}{*}{\multicolumn{5}{|c|}{$\begin{array}{c}\text { Escala Likert } \\
\text { Frequência relativa }(\%)\end{array}$}} & \multicolumn{6}{|c|}{ Escala de ordem de classificação } \\
\hline & \multirow[b]{2}{*}{ Média } & \multirow{2}{*}{ 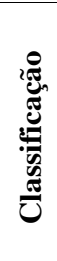 } & \multirow{2}{*}{ 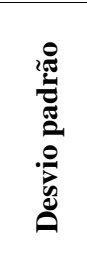 } & & & & & & \multicolumn{3}{|c|}{$\begin{array}{c}\text { Frequência de } \\
\text { escolha }\end{array}$} & \multirow[b]{2}{*}{ 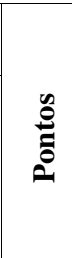 } & \multirow[b]{2}{*}{ 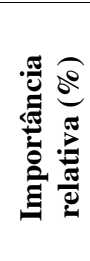 } & \multirow[b]{2}{*}{ 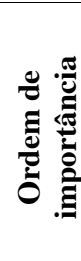 } \\
\hline & & & & 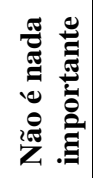 & 党 & 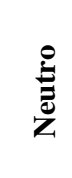 & 冚 & 总总 & 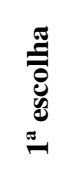 & 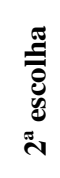 & 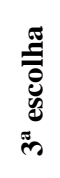 & & & \\
\hline $\begin{array}{l}\text { Proximidade da } \\
\text { instituição de ensino }\end{array}$ & 4,24 & $1^{\mathrm{o}}$ & 0,902 & 1,6 & 2,4 & 14,4 & 33,6 & 48 & 85 & 10 & 11 & 286 & 38,13 & $1^{\mathrm{o}}$ \\
\hline $\begin{array}{l}\text { Proximidade de } \\
\text { supermercados }\end{array}$ & 4,32 & $2^{\circ}$ & 0,736 & 0,8 & 2,4 & 4 & 59,6 & 43,2 & 13 & 62 & 31 & 194 & 25,87 & $2^{\circ}$ \\
\hline $\begin{array}{l}\text { Proximidade de } \\
\text { acesso ao transporte } \\
\text { público }\end{array}$ & 4,08 & $3^{\circ}$ & 1,082 & 4 & 5,6 & 13,6 & 32 & 44,8 & 23 & 21 & 29 & 140 & 18,67 & $3^{\circ}$ \\
\hline $\begin{array}{l}\text { Proximidade de } \\
\text { restaurantes/ } \\
\text { lanchonetes/bares }\end{array}$ & 3,42 & $5^{\circ}$ & 1,002 & 5,6 & 11,2 & 28 & 45,6 & 9,6 & 1 & 11 & 10 & 35 & 4,67 & $4^{\circ}$ \\
\hline $\begin{array}{l}\text { Proximidade de } \\
\text { rodoviária municipal }\end{array}$ & 3,33 & $6^{\circ}$ & 1,022 & 6,4 & 12 & 33,6 & 38,4 & 9,6 & 3 & 3 & 18 & 33 & 4,4 & $5^{\circ}$ \\
\hline $\begin{array}{l}\text { Proximidade de } \\
\text { farmácias }\end{array}$ & 3,78 & $4^{o}$ & 0,912 & 3,2 & 4 & 23,2 & 50,4 & 19,2 & 0 & 8 & 10 & 26 & 3,47 & $6^{\circ}$ \\
\hline $\begin{array}{l}\text { Proximidade de } \\
\text { hospitais }\end{array}$ & 3,24 & $7^{\circ}$ & 0,954 & 5,6 & 10,4 & 47,2 & 28 & 8,8 & 0 & 4 & 11 & 19 & 2,53 & $7^{\circ}$ \\
\hline $\begin{array}{l}\text { Proximidade de } \\
\text { bancos }\end{array}$ & 3,10 & $8^{\circ}$ & 1,061 & 10,4 & 13,6 & 37,6 & 32 & 6,4 & 0 & 5 & 4 & 14 & 1,87 & $8^{\circ}$ \\
\hline $\begin{array}{l}\text { Proximidade de } \\
\text { shoppings }\end{array}$ & 2,15 & $9^{\circ}$ & 0,968 & 31,2 & 31,2 & 28,8 & 8,8 & 0 & 0 & 1 & 1 & 3 & 0,4 & $9^{\circ}$ \\
\hline
\end{tabular}


Tabela 4 - Importância dos requisitos de serviços por escada Likert e escala de ordem de classificação

\begin{tabular}{|c|c|c|c|c|c|c|c|c|c|c|c|c|c|c|}
\hline Requisito & \multicolumn{3}{|c|}{ Medidas } & \multirow{2}{*}{\multicolumn{5}{|c|}{$\begin{array}{c}\text { Escala Likert } \\
\text { Frequência relativa }(\%)\end{array}$}} & \multicolumn{6}{|c|}{ Escala de ordem de classificação } \\
\hline \multirow[b]{2}{*}{ Serviços } & \multirow[b]{2}{*}{$\sum^{\frac{\pi}{2}}$} & \multirow[b]{2}{*}{ 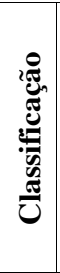 } & \multirow{2}{*}{ 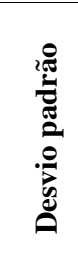 } & & & & & & \multicolumn{3}{|c|}{$\begin{array}{l}\text { Frequência de } \\
\text { escolha }\end{array}$} & \multirow[b]{2}{*}{$\stackrel{\text { ڤ̊ }}{:}$} & \multirow[b]{2}{*}{ 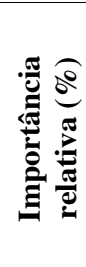 } & \multirow[b]{2}{*}{ 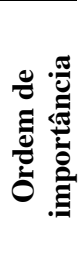 } \\
\hline & & & & 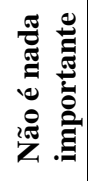 & 艺 & $\stackrel{0}{\grave{Z}}$ & 菢 & 总 & 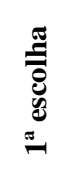 & 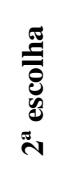 & 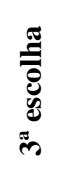 & & & \\
\hline $\begin{array}{l}\text { Internet wi-fi na unidade } \\
\text { (área privativa) }\end{array}$ & 4,66 & $1^{\mathrm{o}}$ & 0,67 & 0 & 2,4 & 4 & 19,2 & 74,4 & 38 & 22 & 17 & 175 & 23,33 & $1^{\mathrm{o}}$ \\
\hline $\begin{array}{l}\text { Recepção } 24 \text { horas por } \\
\text { dia }\end{array}$ & 3,93 & $3^{\circ}$ & 1,14 & 4,8 & 8 & 15,2 & 33,6 & 38,4 & 16 & 22 & 21 & 113 & 15,07 & $2^{\circ}$ \\
\hline $\begin{array}{l}\text { Limpeza da unidade } \\
\text { (área privativa) }\end{array}$ & 3,83 & $5^{\circ}$ & 1,04 & 4 & 5,6 & 22,4 & 39,2 & 28,8 & 19 & 12 & 11 & 92 & 12,27 & $3^{\circ}$ \\
\hline Minimercado/lanches & 3,68 & $7^{\circ}$ & 0,96 & 4,8 & 4,8 & 24 & 50,4 & 16 & 12 & 12 & 18 & 78 & 10,4 & $4^{\circ}$ \\
\hline $\begin{array}{l}\text { Manutenção da unidade } \\
\text { (área privativa) }\end{array}$ & 4,10 & $2^{\circ}$ & 0,88 & 2,4 & 1,6 & 14,4 & 47,2 & 34,4 & 9 & 16 & 12 & 71 & 9,47 & $5^{\circ}$ \\
\hline Serviços de lavanderia & 3,66 & $8^{\circ}$ & 1,11 & 5,6 & 9,6 & 21,6 & 39,2 & 24 & 12 & 11 & 12 & 70 & 9,33 & $6^{\circ}$ \\
\hline Cópias e impressões & 3,66 & $8^{\circ}$ & 1,06 & 4,8 & 10,4 & 19,2 & 45,6 & 20 & 12 & 5 & 8 & 54 & 7,2 & $7^{\circ}$ \\
\hline $\begin{array}{l}\text { Equipe de suporte aos } \\
\text { moradores }\end{array}$ & 3,82 & $6^{\circ}$ & 0,96 & 2,4 & 8 & 17,6 & 48,8 & 23,2 & 3 & 7 & 10 & 33 & 4,4 & $8^{\circ}$ \\
\hline $\begin{array}{l}\text { Internet wi-fi em áreas } \\
\text { comuns }\end{array}$ & 3,88 & $4^{\circ}$ & 1,02 & 3,2 & 5,6 & 22,4 & 37,6 & 31,2 & 2 & 11 & 4 & 32 & 4,27 & $9^{\circ}$ \\
\hline $\begin{array}{l}\text { Disponibilidade de } \\
\text { eventos (festas, palestras, } \\
\text { grupos de esporte, } \\
\text { cinema) }\end{array}$ & 3,21 & $9^{\circ}$ & 1,07 & 9,6 & 9,6 & 41,6 & 28,8 & 10,4 & 1 & 3 & 7 & 16 & 2,13 & $10^{\circ}$ \\
\hline $\begin{array}{l}\text { iFood Box (armário para } \\
\text { armazenamento dos } \\
\text { pedidos) }\end{array}$ & 3,16 & $10^{\circ}$ & 1,07 & 9,6 & 14,4 & 33,6 & 35,2 & 7,2 & 1 & 3 & 1 & 10 & 1,33 & $11^{\circ}$ \\
\hline Aluguel de bicicletas & 2,90 & $11^{\circ}$ & 1,07 & 13,6 & 16,8 & 40 & 24,8 & 4,8 & 0 & 1 & 1 & 3 & 0,4 & $12^{\circ}$ \\
\hline $\begin{array}{l}\text { TV por assinatura na } \\
\text { unidade (área privativa) }\end{array}$ & 2,42 & $12^{\circ}$ & 1,09 & 24,8 & 27,2 & 32 & 12,8 & 3,2 & 0 & 0 & 3 & 3 & 0,4 & $12^{\circ}$ \\
\hline
\end{tabular}

Tabela 5 - Importância dos requisitos de facilidades por escada Likert e escala de ordem de classificação

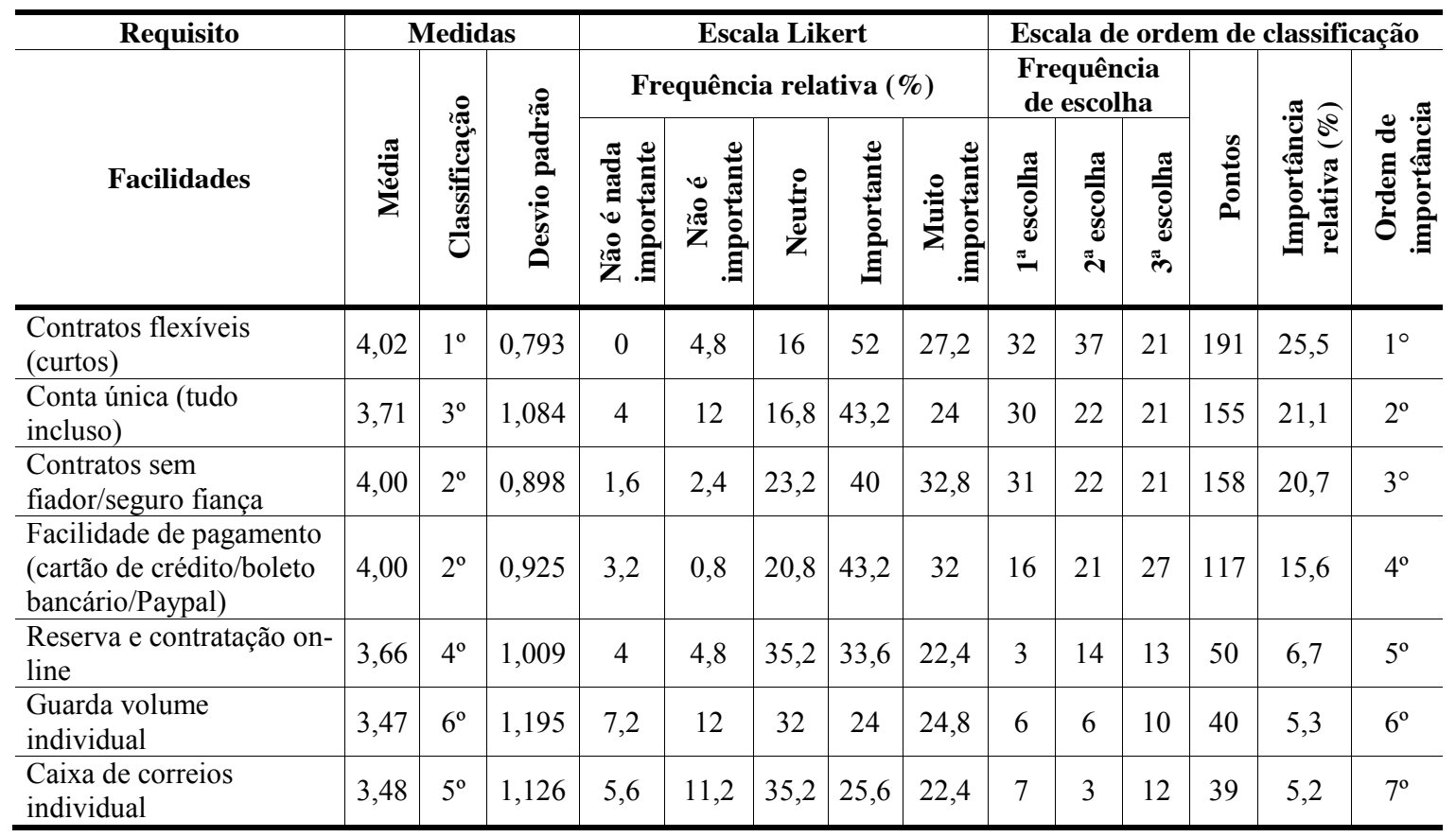

40 Muller, H. M.; Monetti, E.; Marques Neto, J. da C. 
Tabela 6 - Importância dos requisitos de projeto (áreas comuns) por escada Likert e escala de ordem de classificação

\begin{tabular}{|c|c|c|c|c|c|c|c|c|c|c|c|c|c|c|}
\hline \multirow[b]{3}{*}{$\begin{array}{l}\text { Projeto (áreas } \\
\text { comuns) }\end{array}$} & \multicolumn{3}{|c|}{ Medidas } & \multirow{2}{*}{\multicolumn{5}{|c|}{$\begin{array}{c}\text { Escala Likert } \\
\text { Frequência relativa }(\%)\end{array}$}} & \multicolumn{6}{|c|}{ Escala de ordem de classificação } \\
\hline & \multirow[b]{2}{*}{ 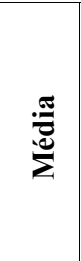 } & \multirow[b]{2}{*}{ 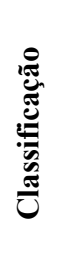 } & \multirow[b]{2}{*}{ 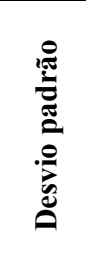 } & & & & & & \multicolumn{3}{|c|}{$\begin{array}{l}\text { Frequência de } \\
\text { escolha }\end{array}$} & \multirow[b]{2}{*}{$\stackrel{\mathscr{E}}{\Xi}$} & \multirow[b]{2}{*}{ 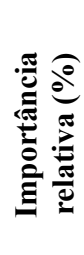 } & \multirow[b]{2}{*}{ 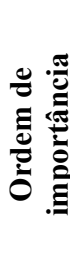 } \\
\hline & & & & 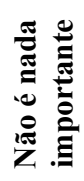 & 品 & 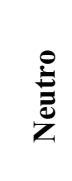 & 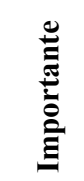 & 䒿 & 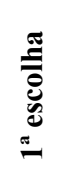 & 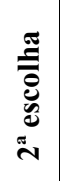 & 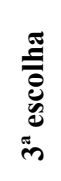 & & & \\
\hline Sala de estudos & 3,95 & $1^{\circ}$ & 1,061 & 3,2 & 8,8 & 12,8 & 40 & 35,2 & 40 & 17 & 21 & 175 & 23,3 & $1^{\circ}$ \\
\hline Academia/área fitness & 3,49 & $2^{\circ}$ & 1,112 & 8 & 9,6 & 23,2 & 44 & 15,2 & 37 & 17 & 17 & 162 & 21,6 & $2^{\circ}$ \\
\hline $\begin{array}{l}\text { Área de festas com } \\
\text { churrasqueira }\end{array}$ & 3,41 & $3^{\circ}$ & 1,101 & 8 & 9,6 & 30,4 & 37,6 & 14,4 & 15 & 20 & 10 & 95 & 12,7 & $3^{\circ}$ \\
\hline $\begin{array}{l}\text { Área de convívio/ } \\
\text { solário/jardim }\end{array}$ & 3,33 & $4^{\mathrm{o}}$ & 1,053 & 8 & 9,6 & 34,4 & 37,6 & 10,4 & 7 & 19 & 17 & 76 & 10,1 & $4^{\mathrm{o}}$ \\
\hline Área comum no andar & 2,90 & $8^{\circ}$ & 0,949 & 8 & 23,2 & 43,2 & 22,4 & 3,2 & 10 & 8 & 4 & 50 & 6,7 & $5^{\circ}$ \\
\hline $\begin{array}{l}\text { Cozinha } \\
\text { compartilhada/ } \\
\text { comunitária }\end{array}$ & $\begin{array}{c}2,78 \\
\text { o }\end{array}$ & $10^{\circ}$ & 1,25 & 21,6 & 18,4 & 28,8 & 23,2 & 8 & 6 & 10 & 10 & 48 & 6,4 & $6^{\circ}$ \\
\hline Piscina & 2,94 & $7^{\circ}$ & 1,065 & 13,6 & 14,4 & 40 & 28 & 4 & 2 & 10 & 17 & 43 & 5,7 & $7^{\circ}$ \\
\hline Coworking & 3,27 & $5^{\circ}$ & 0,995 & 6,4 & 12,8 & 35,2 & 38,4 & 7,2 & 5 & 10 & 3 & 38 & 5,1 & $8^{\circ}$ \\
\hline Sala de eventos & 3,04 & $6^{\circ}$ & 1,117 & 12,8 & 13,6 & 38,4 & 27,2 & 8 & 3 & 5 & 5 & 24 & 3,2 & $9^{\circ}$ \\
\hline Sala de jogos & 2,81 & $9^{\circ}$ & 1,148 & 17,6 & 17,6 & 37,6 & 20,8 & 6,4 & 0 & 2 & 11 & 15 & 2 & $10^{\circ}$ \\
\hline Espaço de yoga & 2,54 & $12^{\circ}$ & 1,168 & 25,6 & 19,2 & 36,8 & 12,8 & 5,6 & 0 & 5 & 4 & 14 & 1,9 & $11^{\circ}$ \\
\hline Sala de cinema & 2,54 & $12^{\circ}$ & 1,036 & 20,8 & 22,4 & 41,6 & 12,8 & 2,4 & 0 & 1 & 4 & 6 & 0,8 & $12^{\circ}$ \\
\hline Lounge com TV & 2,56 & $11^{\circ}$ & 1,132 & 21,6 & 24,8 & 35,2 & 12,8 & 5,6 & 0 & 1 & 2 & 4 & 0,5 & $13^{\circ}$ \\
\hline
\end{tabular}

Com relação às áreas privativas, os resultados ilustrados na Tabela 7 mostram que, em geral, existe uma importância superior nos quesitos quarto individual, banheiro privativo, apartamento mobiliado e equipado, e copa/cozinha privativa, uma vez que esses tópicos obtiveram os valores médios mais elevados na escala Likert.

Tais achados se equiparam aos resultados apresentados por La Roche, Flanigan e Copeland Junior (2010), que relatam a importância de quartos e banheiros privativos, assim como o estudo de Brandli e Heineck (2005), que identificou a importância da privacidade de espaço, com independência no uso do banheiro e cozinha, bem como a preferência dos estudantes por habitações mobiliadas. Por outro lado, consideram-se menos importantes os atributos, ar condicionado, fechadura eletrônica e varanda/sacada. Nessa análise, a avaliação por escala de classificação não foi considerada porque nem todos os atributos têm um grau de semelhança comparativa.

\section{Proposta de diretrizes gerais}

As diretrizes têm como intenção auxiliar os agentes do mercado imobiliário estudantil, sendo estes projetistas, incorporadores ou investidores no processo de desenvolvimento de seus produtos, de modo a identificar quais requisitos são considerados essenciais e importantes do ponto de vista dos estudantes, bem como outras recomendações significativas a serem consideradas. Para isso, criam-se doze diretrizes divididas em quatro grupos de assuntos:
(a) requisitos de mensalidade;
(b) requisitos de localização;
(c) requisitos de serviços e facilidades; e
(d) requisitos de projeto, como pode ser visto na Figura 4. 
Tabela 7 - Importância dos requisitos de projeto (áreas privativas) por escada Likert

\begin{tabular}{|c|c|c|c|c|c|c|c|c|}
\hline \multirow[b]{3}{*}{ Projeto (áreas privativas) } & \multicolumn{3}{|c|}{ Medidas } & \multirow{2}{*}{\multicolumn{5}{|c|}{$\begin{array}{c}\text { Escala Likert } \\
\text { Frequência relativa }(\%)\end{array}$}} \\
\hline & \multirow[b]{2}{*}{ 笨 } & \multirow[b]{2}{*}{ 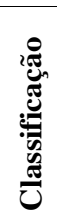 } & \multirow[b]{2}{*}{ 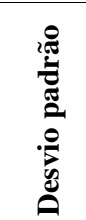 } & & & & & \\
\hline & & & & 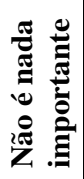 & 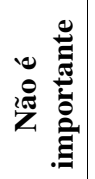 & $\begin{array}{l}\stackrel{D}{E} \\
\text { Z }\end{array}$ & 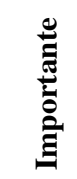 & 参总 \\
\hline Quarto individual & 4,47 & $1^{\circ}$ & 0,736 & 0,0 & 1,6 & 9,6 & 28,8 & 60,0 \\
\hline Apartamento mobiliado & 4,42 & $2^{\circ}$ & 0,805 & 1,6 & 1,6 & 5,6 & 36,0 & 55,2 \\
\hline Banheiro individual & 4,26 & $3^{\circ}$ & 0,879 & 0,0 & 4,0 & 13,6 & 34,4 & 48,0 \\
\hline $\begin{array}{l}\text { Apartamento equipado (eletrodomésticos } \\
\text { e utensílios) }\end{array}$ & 4,26 & $3^{\circ}$ & 0,879 & 2,4 & 1,6 & 9,6 & 40,8 & 45,6 \\
\hline Cozinha/copa privativa & 3,92 & $4^{\circ}$ & 0,98 & 0,0 & 9,6 & 23,2 & 32,8 & 34,4 \\
\hline Varanda/sacada & 3,22 & $5^{\circ}$ & 1,097 & 8,8 & 13,6 & 36,0 & 30,4 & 11,2 \\
\hline Fechadura eletrônica & 3,14 & $6^{\circ}$ & 1,173 & 10,4 & 16,8 & 36,0 & 22,4 & 14,4 \\
\hline Ar condicionado & 3,10 & $7^{\circ}$ & 1,167 & 11,2 & 16,0 & 38,4 & 20,8 & 13,6 \\
\hline
\end{tabular}

Figura 4 - Resumo das diretrizes para o desenvolvimento de empreendimentos Student Housing

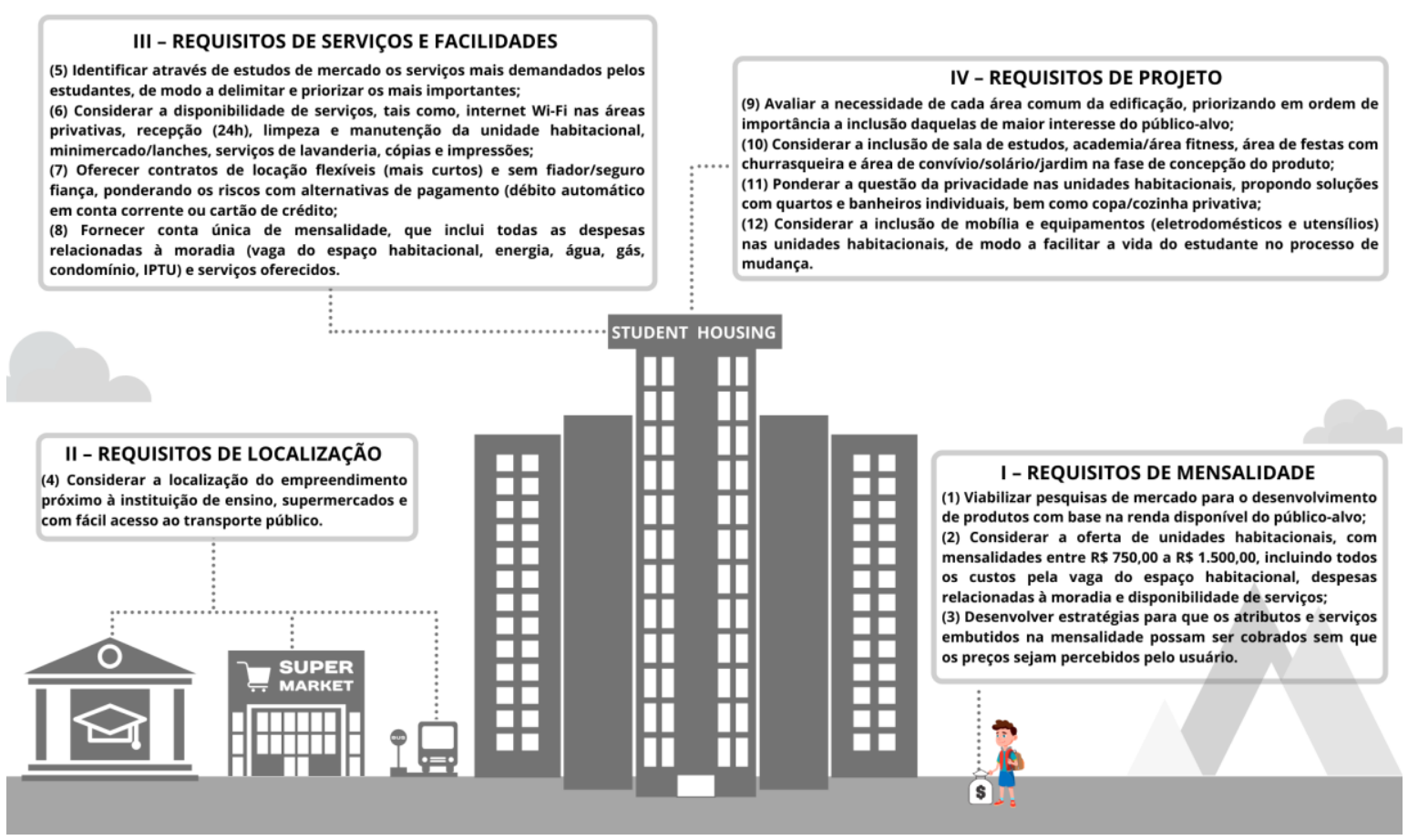

42 Muller, H. M.; Monetti, E.; Marques Neto, J. da C. 


\section{Grupo I: requisitos de mensalidade}

$\mathrm{O}$ valor da mensalidade a ser cobrada pelo espaço das unidades habitacionais deve estar em conformidade com a renda disponível do público-alvo. Os custos com aluguel e despesas relacionados à moradia (internet, água, gás, condomínio, lavanderia e limpeza) é um dos principais fatores considerados no processo de escolha da moradia pelos estudantes. Nesta pesquisa, grande parte dos participantes disse possuir renda disponível para o aluguel de até $\mathrm{R} \$ 500,00$ ou entre $\mathrm{R} \$ 501,00$ e $\mathrm{R} \$ 1.000,00$, assim como a renda disponível para gastos relacionados à moradia de até $R \$ 250,00$ ou entre $R \$ 251,00$ e $R \$ 500,00$.

Dessa forma, os menores e maiores valores ${ }^{3}$ possíveis das rendas somadas (aluguel e gastos relacionados à moradia) são $\mathrm{R} \$ 750,00$ e $\mathrm{R} \$ 1.500,00$, respectivamente.

Ademais, desenvolver estratégias de mercado que possam agregar valor ao usuário, cobrando pelos atributos e serviços oferecidos sem que os preços sejam percebidos, é essencial para a obtenção de vantagens competitivas. Por exemplo, ao disponibilizar um pacote de mensalidade, incluindo vários serviços, sejam eles embutidos ou opcionais, tais como: internet, limpeza, manutenção, recepção (24 horas), minimercado/lanches, lavanderia, cópias e impressões, permite maiores comodidades aos usuários, possibilitando que eles paguem por isso. Para os desenvolvedores, há possibilidade do aumento de receitas, não apenas proveniente da vaga pela unidade habitacional, mas também desse conjunto de serviços, que, em circunstâncias comuns do mercado imobiliário de aluguel, teria que ser contratado separadamente pelo usuário. De maneira similar, a academia/área fitness pode ser apresentada como um serviço, não apenas como uma área comum da edificação.

Sendo assim, cabe ao desenvolvedor criar suas estratégias para o aumento de receitas, oferecendo serviços e comodidades de interesse e de acordo com a capacidade financeira do público-alvo.

\section{Grupo II: requisitos de localização}

A localização do imóvel mostrou-se como outro fator considerado muito importante no processo de escolha da moradia. Os desenvolvedores de empreendimentos para estudantes devem priorizar a implantação - ou aquisição de imóveis já existentes para tal finalidade - em lugares próximos da instituição de ensino, próximos de supermercados e próximos de acesso ao transporte público.

\section{Grupo III: requisitos de serviços e facilidades}

A oferta de serviços em empreendimentos para estudantes é um diferencial dos empreendimentos SH, contudo, para atender às necessidades dos estudantes deve-se identificar, através de estudos de mercado, os serviços mais demandados pelo público-alvo e priorizá-los. Dentre os serviços listados nesta pesquisa, recomenda-se que os desenvolvedores ofertem os seguintes serviços:

(a) internet wi-fi na unidade (área privativa);

(b) recepção (24 horas);

(c) limpeza da unidade (área privativa);

(d) minimercado/lanches;

(e) manutenção da unidade;

(f) serviços de lavanderia; e

(g) cópias e impressões - nesta ordem de importância.

As facilidades permitem minimizar processos burocráticos de contratos, agilizando a locação das unidades do empreendimento, além de oferecer benefícios aos usuários. A presente pesquisa mostrou que as facilidades mais importantes, segundo os estudantes, são: contratos flexíveis (mais curtos), contratos sem fiador/seguro fiança, conta única (tudo incluso), nesta ordem de importância.

Dessa forma, o desenvolvedor deve avaliar a flexibilidade, com contratos e formas de pagamento que aliem as necessidades dos estudantes, ponderando os riscos. Alternativas de pagamento recorrente com débito automático em conta corrente ou cartão de crédito devem ser consideradas, pois têm menos chance de

${ }^{3}$ Valores referentes ao ano de 2020. Salário mínimo: R\$ 1.045,00. 
inadimplência, permitem projeções financeiras, trazem facilidades aos usuários, evitando a preocupação com o pagamento e bloqueio do limite do cartão de crédito.

\section{Grupo IV: requisitos de projeto}

Os empreendimentos devem ser projetados contendo áreas comuns que são de interesse e que atendam às necessidades do público-alvo. Portanto, recomenda-se priorizar a inclusão das seguintes áreas comuns, em ordem de importância: sala de estudos, academia/área fitness, áreas de festas com churrasqueira e área de convívio/solário/jardim.

Com relação às áreas privativas, quando possível, as unidades habitacionais devem ser projetadas para dispor de quartos individuais, com banheiro individual e copa/cozinha privativa. Além disso, considera-se importante que as unidades sejam mobiliadas e equipadas com eletrodomésticos e utensílios.

\section{Conclusão}

Os achados nesta pesquisa mostram que, embora o modelo $\mathrm{SH}$ apresente-se como inovador, diversos atributos inclusos nos empreendimentos brasileiros com essa característica não são considerados como importantes ou são indiferentes do ponto de vista dos estudantes, por exemplo:

(a) áreas comuns (lounge com TV, sala de cinema, espaço de yoga, sala de jogos, sala de eventos, coworking, piscina, cozinha comunitária, área comum no andar);

(b) serviços (TV por assinatura, aluguel de bicicletas, iFood Box e disponibilidade de eventos); e

(c) facilidades (caixa de correio e guarda volume individual).

Em contrapartida, muitos outros itens foram considerados essenciais, como, por exemplo:

(a) localização (proximidade da moradia à IES, proximidade de supermercados, e com fácil acesso ao transporte público);

(b) facilidades (contratos flexíveis (curtos);

(c) conta única (tudo incluso), contratos sem fiador/seguro fiança e facilidade de pagamento);

(d) serviços (internet wi-fi na unidade (área privativa), recepção (24 horas), limpeza e manutenção da unidade (área privativa), minimercado/lanches, serviços de lavanderia, serviços de cópias e impressões, internet wi-fi em áreas comuns e equipe de suporte aos moradores);

(e) áreas comuns (sala de estudos, academia/áreas fitness, área de festas com churrasqueira, e área de convívio/solário/jardim);

(f) áreas privadas (quartos e banheiros individuais, copa/cozinha privativa, bem como mobiliário e equipamentos (utensílios e eletrodomésticos) nas unidades habitacionais); $\mathrm{e}$

(g) mensalidade (orçamento para despesas com aluguel de até $\mathrm{R} \$ 1.000,00$, e orçamento disponível para despesas relacionados à moradia de até $\mathrm{R} \$ 500,00)$.

Nesse sentido, é importante que os projetistas identifiquem os valores, necessidades e desejos dos usuários, a fim de garantir que estes estejam satisfeitos com sua habitação, evitando assim a repetição de problemas e falhas no ambiente construído. Do ponto de vista do empreendedor que deseja investir em edifícios SH, cabe destacar algumas recomendações. Primeiramente, é importante que o empreendedor identifique quais os riscos da geração de receita desse negócio para que possa se proteger em eventuais flutuações ao longo do tempo. Também é importante compreender as leis de locação, tendo em vista que o produto se assemelha em partes com a atividade de hotelaria e, ao mesmo tempo, com a residencial - o que pode se enquadrar em um contrato de locação residencial ou até mesmo em um contrato de prestação de serviço de hospedagem. Por fim, recomenda-se que o empreendedor identifique estratégias para que os atributos e serviços possam ser embutidos nas mensalidades, sem que o preço possa ser reconhecido pelo usuário, para que, dessa maneira, ele aceite pagar por eles de acordo com sua capacidade financeira.

Cabe destacar que a pesquisa se limitou à quantidade de participantes e à população pesquisada, concentrando apenas em alunos de IES que estudam em São Carlos, SP. Contudo, o assunto mostrou-se abrangente e os procedimentos metodológicos pertinentes, podendo ser aplicados em diferentes localidades e grupos de estudantes. Espera-se que as diretrizes propostas neste estudo possam contribuir para a produção de edifícios mais assertivos, que se preocupam com a qualidade do ambiente construído, satisfaçam as 
necessidade e desejos dos usuários, e garantam maior competitividade para os investidores. Por fim, esperase que o presente estudo venha a servir como motivação e embasamento teórico para futuros trabalhos, tendo em vista a relevância e a importância do mercado imobiliário para estudantes, assunto ainda pouco discutido no âmbito da investigação nacional.

\section{Referências}

AMOLE, D. Residential satisfaction in students' housing. Journal of Environmental Psychology, v. 29, n. 1, p. 76-85, mar. 2009.

BRANDLI, L. L. Modelo de demanda habitacional de estudantes numa perspectiva de desenvolvimento local. Florianópolis, 2004. 308 f. Tese (Doutorado em Engenharia de Produção) Universidade Federal de Santa Catarina, Florianópolis, 2004.

BRANDLI, L. L.; HEINECK, L. F. M. As Abordagens dos modelos de preferência declarada e revelada no processo de escolha habitacional. Ambiente Construído, Porto Alegre, v. 5, n. 2, p. 61-75, abr./jun. 2005.

CARVALHO, F. A. de; LEITE, V. F. Attribute importance in service quality: an empirical test of the pbz conjecture in Brazil: an empirical test of the PBZ conjecture in Brazil. International Journal of Service Industry Management, v. 10, n. 5, p. 487-504, dez. 1999.

ETIKAN, I.; MUSA, S. A.; ALKASSIM, R. S. Comparison of convenience sampling and purposive sampling. American Journal of Theoretical and Applied Statistics, v. 5, n. 1, p. 1, 2016.

FIELDS, T. J. et al. A hedonic model for off-campus student housing: the value of proximity to campus. Housing and Society, v. 40, n. 1, p. 39-58, jan. 2013.

FRENCH, N. et al. Investment opportunities for student housing in Europe. Journal of Property Investment e Finance, v. 36, n. 6, p.578-584, 3 set. 2018.

GARRIDO, E. N. Moradia estudantil e formação do(a) estudante universitário(a). Campinas, 2012. 284 f. Tese (Doutorado em Educação) - Curso de Psicologia Educacional, Universidade Estadual de Campinas, Campinas, 2012.

HENSHER, D. A.; TAYLOR, A. K. Intraurban residential relocation choices for students: an empirical inquiry. Environment and Planning A: Economy and Space, v. 15, n. 6, p. 815-830, jun. 1983.

INSTITUTO BRASILEIRO DE GEOGRAFIA E ESTATÍSTICA. Projeção da população do Brasil e das Unidades da Federação. Disponível em: https://www.ibge.gov.br/apps/populacao/projecao/. Acesso em: 30 abr. 2020 .

INSTITUTO NACIONAL DE ESTUDOS E PESQUISAS EDUCACIONAIS ANÍSIO TEIXEIRA. Censo da Educação Superior 2018: notas estatísticas. Brasília, 2019. Disponível em:

http://download.inep.gov.br/educacao_superior/censo_superior/documentos/2019/censo_da_educacao_super ior_2018-notas_estatisticas.pdf. Acesso em: 30 abr. 2020.

JONES LANG LASALLE (org.). Alternative predictions survey 2017. London: Jones Lang Lasalle, 2017. Disponível em: http://viewer.zmags.com/publication/9070f1fd\#/9070f1fd/1. Acesso em: 5 jun. 2019

KHOZAEI, F. et al. Examination of student housing preferences, their similarities and differences. Facilities, v. 32, n. 11/12, p.709-722, 4 ago. 2014.

KOWALKOWSKI, C. et al. Servitization and deservitization: overview, concepts, and definitions. Industrial Marketing Management, v. 60, p.4-10, jan. 2017.

LA ROCHE, C. R.; FLANIGAN, M. A.; COPELAND JUNIOR, P. K. Student Housing: trends, preferences and needs. Contemporary Issues in Education Research (CIER), v. 3, n. 10, p. 45-50, out. 2010.

LACERDA, I. P.; VALENTINI, F. Impacto da moradia estudantil no desempenho acadêmico e na permanência na universidade. Psicologia Escolar e Educacional, v. 22, n. 2, p. 413-423, ago. 2018.

LANDIS, J. R.; KOCH, G. G. The measurement of observer agreement for categorical data. Biometrics, v. 33, n. 1, p. 159, mar. 1977.

LOUVIERE, J. J.; HENLEY, D. A. Information integration theory applied to student apartment selection decisions. Geographical Analysis, v. 9, n. 2, p. 130-141, abr. 1977. 
MALHOTRA, N. K.; NUNAN, D; BIRKS, D. F. Marketing research: and applied approach. 6. ed. Harlow: Pearson, 2017.

MCBRIDE, Y. Future of student housing: meeting emerging student needs. On the Horizon, v. 25, n. 3, p. 190-196, ago. 2017.

MIGUEL, P. A. C. (org.). Metodologia de pesquisa em engenharia de produção e gestão de operações. 2. ed. Rio de Janeiro: Elsevier, 2012.

MOORE, H. P. et al. Residential satisfaction among college students: examining high-end amenity Student Housing. Family and Consumer Sciences Research Journal, v. 47, n. 3, p. 260-275, mar. 2019.

OSSE, C. M. C.; COSTA, I. I. Saúde mental e qualidade de vida na moradia estudantil da Universidade de Brasília. Estudos de Psicologia, Campinas, v. 28, n. 1, p. 115-122, mar. 2011.

PETRI, R. G. The Brazilian student housing market: an exploratory study. São Paulo, 2016.87 f. Dissertação (Mestrado Profissional em Gestão Internacional) - Curso de Master in International Management, Escola de Administração de Empresas de São Paulo, São Paulo, 2016.

ROCHA LIMA JUNIOR, J. D.; MONETTI, E.; ALENCAR, C. T. D. Real Estate fundamentos para análise de investimentos. Rio de Janeiro: Elsevier, 2011.

RUGG, J.; RHODES, D.; JONES, A. Studying a Niche Market: UK students and the private rented sector: UK students and the private rented sector. Housing Studies, v. 17, n. 2, p. 289-303, mar. 2002.

SAVILLS (org.). Global Student Housing Investment. London: Savills Research, 2019. Disponível em: https://pdf.euro.savills.co.uk/global-research/spotlight---global-student-housing-investment-2019.pdf. Acesso em: 8 jun. 2019.

SHAFER, S. M.; SMITH, H. J.; LINDER, J. C. The power of business models. Business Horizons, v. 48, n. 3, p. 199-207, maio 2005.

SHARE STUDENT LIVING (org.). Propriedades. Disponível em: http://sharesl.com.br/. Acesso em: 20 jan. 2020.

SHINN, A. M. Measuring the utility of housing: demonstrating a methodological approach. Social Science Quartely, v. 52, n. 1, p. 88-102, jun. 1971.

SUGDEN, R; WILLIAMS, A. The location choice of students in lodgings and flats. Urban Studies, v. 10, p. 87-90, 1973.

TEECE, D. J. Business models, business strategy and innovation. Long Range Planning, v. 43, n. 2/3, p. 172-194, abr. 2010.

THOMSEN, J.; EIKEMO, T. A. Aspects of student housing satisfaction: a quantitative study. Journal of Housing and the Built Environment, v. 25, n. 3, p. 273-293, mar. 2010.

ULIVING BRASIL (org.). Unidades. Disponível em: https://uliving.com.br/. Acesso em: 18 jan. 2020.

VANDERMERWE, S.; RADA, J. Servitization of business: adding value by adding services. European Management Journal, v. 6, n. 4, 1988.

ZANCUL, J. S. Habitação Estudantil: avaliação pós-ocupação em São Carlos - SP. São Carlos, 2007. Dissertação (Mestrado em Arquitetura e Urbanismo) - Escola de Engenharia de São Carlos, Universidade de São Paulo, São Carlos, 2007.

\section{Agradecimentos}

O presente trabalho foi realizado com apoio da Coordenação de Aperfeiçoamento de Pessoal de Nível Superior - Brasil (Capes) - Código de Financiamento 001. 
Hyago Mauricio Bremm Muller

Programa de Pós-Graduacão em Engenharia Civil, Departamento de Engenharia Civil | Universidade Federal de São Carlos | Rod. Washington Luiz, Km 235, SP 310, Monjolinho | São Carlos - SP - Brasil | CEP 13565-905 | Tel.: (66) 99958-6755 | E-mail: hyagomuller@gmail.com

\section{Eliane Monetti}

Departamento de Engenharia de Construção Civil, Escola Politécnica | Universidade de São Paulo | Av. Prof. Almeida Prado, Trav. 2, 83, Sala 48, Cidade Universitária | São Paulo - SP - Brasil | CEP 05508-900 | Tel.: (11) 98421-2821 | E-mail: eliane.monetti@usp.br

\section{José da Costa Marques Neto}

Programa de Pós-Graduação em Engenharia Civil, Departamento de Engenharia Civil | Universidade Federal de São Carlos | Tel.: (16) 99214-0130 | E-mail: joseneto@ufscar.br

\section{Ambiente Construído}

Revista da Associação Nacional de Tecnologia do Ambiente Construído

Av. Osvaldo Aranha, $99-3^{\circ}$ andar, Centro

Porto Alegre - RS - Brasil

$$
\text { CEP 90035-190 }
$$

Telefone: +55 (51) 3308-4084

www.seer.ufrgs.br/ambienteconstruido www.scielo.br/ac

E-mail: ambienteconstruido@ufrgs.br

This is an open-access article distributed under the terms of the Creative Commons Attribution License. 